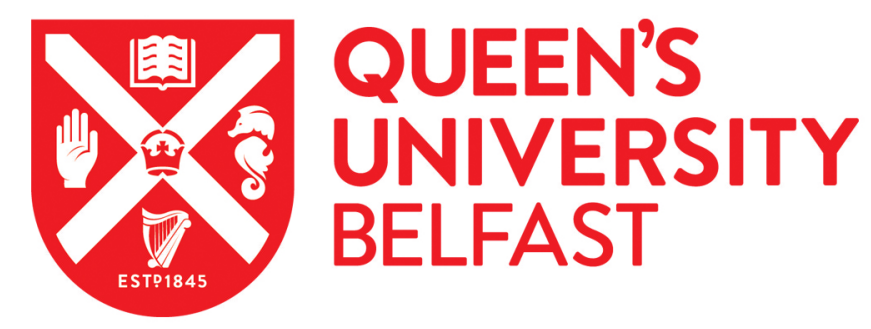

\title{
Predicting the crushing behaviour of composite material using high- fidelity finite element modelling
}

Tan, W., Falzon, B. G., \& Price, M. (2015). Predicting the crushing behaviour of composite material using highfidelity finite element modelling. International Journal of Crashworthiness, 20(1), 60-77.

https://doi.org/10.1080/13588265.2014.972122

Published in:

International Journal of Crashworthiness

Document Version:

Peer reviewed version

Queen's University Belfast - Research Portal:

Link to publication record in Queen's University Belfast Research Portal

Publisher rights

Copyright 2014 Taylor \& Francis.

This is an Accepted Manuscript of an article published by Taylor \& Francis in the International Journal of Crashworthiness on 07/11/2014, available online: http://wwww.tandfonline.com/10.1080/13588265.2014.972122.

\section{General rights}

Copyright for the publications made accessible via the Queen's University Belfast Research Portal is retained by the author(s) and / or other copyright owners and it is a condition of accessing these publications that users recognise and abide by the legal requirements associated with these rights.

Take down policy

The Research Portal is Queen's institutional repository that provides access to Queen's research output. Every effort has been made to ensure that content in the Research Portal does not infringe any person's rights, or applicable UK laws. If you discover content in the Research Portal that you believe breaches copyright or violates any law, please contact openaccess@qub.ac.uk. 
Predicting the crushing behaviour of composite material using high-fidelity finite element modelling

Wei Tan, Brian G. Falzon*, Mark Price

School of Mechanical and Aerospace Engineering, Queen's University Belfast, Ashby Building, Belfast, BT9 5AH, UK

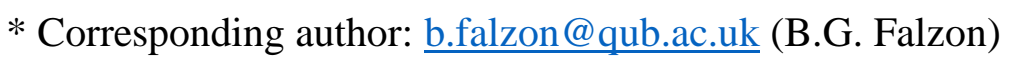

Tel: +44(0)2890975640 


\title{
Predicting the crushing behaviour of composite material using high-fidelity finite element modelling
}

\begin{abstract}
The capability to numerically model the crushing behaviour of composite structures will enable the efficient design of structures with high specific energy absorption capacity. This is particularly relevant to the aerospace and automotive industries where cabin structures need to be shown to be crashworthy. In this paper, a three-dimensional damage model is presented, which accurately represents the behaviour of composite laminates under crush loading. Both intralaminar and interlaminar failure mechanisms are taken into account. The crush damage model was implemented in
\end{abstract} ABAQUS/Explicit as a VUMAT subroutine. Numerical predictions are shown to agree well with experimental results, accurately capturing the intralaminar and interlaminar damage for a range of stacking sequences, triggers and composite materials. The use of measured material parameters required by the numerical models, without the need to 'calibrate' this input data, demonstrates this computational tool's predictive capabilities.

Keywords: damage mechanics; finite element analysis; crushing response; composite damage model

\section{Introduction}

Composite materials are finding increasing utilisation in a number of transportation industries concerned with making structures lighter to reduce environmental impact and improve efficiency. The aerospace industry [38] has been at the forefront of this endeavour with the automotive [24] and railway industries [7] embarking on similar strategies. A major challenge in the development of land-based mass-transportation fibre-reinforced polymer composite vehicles is ensuring a prescribed level of crashworthiness [27]. Crashworthiness is the ability of a structure to protect its occupants during a crash event. While the potential superior energy absorbing capacity of carbon-fibre composite structures is repeatedly demonstrated in Formula One racing [9], the design of a cost-effective crashworthy carbonfibre reinforced polymer (CFRP) automotive passenger cabin has yet to be realised. 
Composite structures typically fail through a complex sequence of interacting fracture mechanisms involving fibre pullout/fracture, matrix cracking and delamination. The actual mechanism and sequence of damage are highly dependent on the mechanical properties [33], geometry [42], lamina orientation [40, 53], trigger mechanisms [23, 44, 57] and, depending on the constituent materials, strain rate; e.g., while strain rate effects are not significant in carbon-fibre thermoset composites, they are in glass-fibre composites [5]. A number of these properties can be tailored to develop high energy absorbing crashworthy components.

However, current assessment of composite structures, under crush loading, relies on extensive, costly and time-consuming experimental testing [20, 25, 29, 35, 42, 44-46, 58, 59]. It is therefore desirable to develop a cost-effective computational approach to predict the response of composite structures during crushing. Many researchers have made efforts to improve the accuracy of numerical models for simulating composite crushing, using finite element analysis [31, 41, 60]. Kiani et al. [32] employed shell elements to study the crashworthiness of pultruded glass-polyester tubes under axial impact loading, in LS-DYNA, and investigated the sensitivity of the major modelling parameters. A continuum damage mechanics based model, also implemented in LS-DYNA, was used by McGregor et al. [39] to simulate the damage propagation and energy absorption in the dynamic crushing of braided composite tubes. A similar model, presented by Sokolinsky et al. [56], investigated a corrugated carbon-epoxy fabric composite plate subjected to quasi-static crushing, where the intralaminar failure and the delamination response were simulated using in-built damage and cohesive surface laws in ABAQUS/Explicit. A steeple-type triggering mechanism, which ensures a continuous stable crushing mode of failure, was used to simulate the response of self-supporting carbon-epoxy hat-shaped crush elements with the software package PAMCRASH [28, 29]. A plug-in tool for ABAQUS/Explicit, CZone, which is dependent on empirical coupon and component data to generate input parameters for the computational 
model, was employed to simulate the crushing of large scale structures [55]. CZone handles the material behaviour at the crush front, while the in-built failure model in ABAQUS deals with the integrity of the surrounding structure.

Other investigators have developed more accurate approaches on the basis of improved interlaminar and intralaminar damage models. Pinho et al. [47] proposed a numerical model for the crushing simulation of fibre-reinforced composite materials. The propagation was modelled using cohesive elements to account for the energy involved in the crushing process. Palanivelu et al. [43] used cohesive elements in an axial impact loading on circular and square cross sectional pultruded composite tubes, focusing on the numerical modelling of triggering. A cohesive element formulation was also employed by Fleming [18] to model composite crush initiation. An energy-based constitutive model was employed by Chiu et al. [11] to model the behaviour of carbon fibre reinforced epoxy resin composite material under crush loading. New contributions were made to this model [15] to enhance its performance under complex loading and damage interaction. Israr et al. [26] presented a pseudo-2D finite element model for mixed-mode crushing in laminated plates by introducing a free-face-crushing concept to represent localized crushing, similar to a strain-based element deletion criterion.

To validate these composite damage models, many self-supporting specimens such as tubes [39], tube segment [28], corrugated [20, 56] and hat-shaped specimens [29] were typically utilized. Nonetheless, circular or corrugated shapes are comparatively difficult to manufacture and to deduce the material failure features. Alternatively, a simple wedge specimen was designed $[21,25,26]$, which is adequate for understanding the failure behaviour, under crushing, by investigating the crushing morphology, specific energy absorption (SEA) and force-displacement curve. This paper will further show the appropriateness of these test specimens for model validation. 
In this context, improvements have been made to the composite damage model by Falzon et al. [11, 14-16], which include a unified matrix damage initiation criterion, mixedmode intralaminar damage progression and a robust element deletion strategy, to simulate the crushing process on wedge specimens of different composite material, lay-up and trigger chamfer angle. The predictive capabilities of the model are confirmed by validating with experimental results obtained from the literature $[21,25,26]$.

\section{Composite damage model}

\subsection{Constitutive law}

Various intralaminar composite damage models have been presented in the literature in recent years, focusing on the application of continuum damage mechanics (CDM) as proposed by Kachanov [30] and further developed by Lemaitre and Chaboche [36]. A number of the computational damage models reported, have also adopted Puck and Shurmann's [51] phenomenological methodology for determining the initiation of matrix fracture. Contributions to the characterisation of longitudinal (fibre-dominated) compressive failure were reported by Pinho et al. [48]. Donadon et al. [13] and Falzon et al. [14-16] presented a three dimensional (3D) CDM-based material model to investigate the progressive intralaminar degradation of composite laminates.

This approach makes use of an effective stress tensor, $\tilde{\sigma}$, which represents the stresses transmitted across the intact part of the cross-section in a Representative Volume Element (RVE) and is related to the true stress tensor, $\sigma$, by a damage tensor, $\boldsymbol{D}$,

$$
\sigma=\boldsymbol{D} \tilde{\sigma}
$$

The damage tensor is a function of three monotonically increasing damage variables, bound by 0 (no damage) and 1 (complete failure), each one relating to a form of damage mode under a different loading state. $d_{11}^{T}$ refers to tensile damage in the fibre direction, $d_{11}^{C}$ refers to 
compressive damage in the fibre direction and $d_{\text {mat }}$ refers to matrix cracking due to a combination of transverse tension/compression and shear loading.

Assuming strain equivalence, the undamaged material elasticity matrix, $\mathbf{C}$, relates the strain tensor to the effective stress tensor,

$$
\tilde{\sigma}=\mathbf{C} \varepsilon,
$$

where

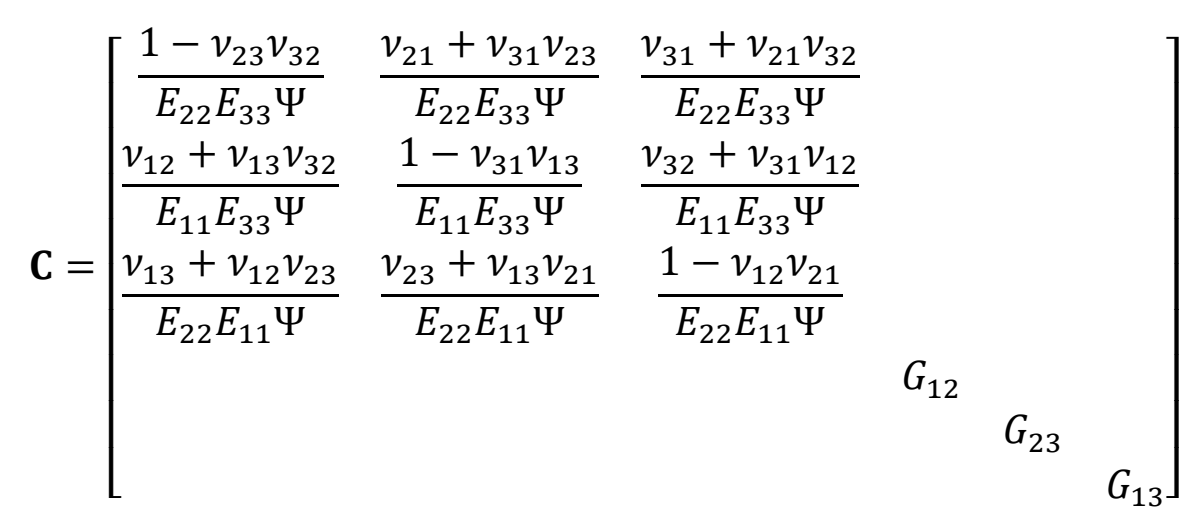

and $\quad \Psi=\frac{1-v_{12} v_{21}-v_{23} v_{32}-v_{31} v_{13}-2 v_{12} v_{23} v_{31}}{E_{11} E_{22} E_{33}}$.

Combining Eq. 1 and 2 leads to:

$$
\sigma=D C \varepsilon
$$

In order to maintain a positive definite elasticity matrix, $\boldsymbol{C}$, the Poisson's ratios must also be degraded when damage has initiated,

$$
\frac{v_{i j, d}}{E_{i i, d}}=\frac{v_{i j}(1-d)}{E_{i i}(1-d)}=\frac{v_{j i}(1-d)}{E_{j j}(1-d)}=\frac{v_{j i, d}}{E_{j j, d}}, i, j=1,2,3
$$

where $d$ is either $d_{11}^{T}, d_{11}^{C}$ or $d_{\text {mat }}$.

\subsection{Intralaminar damage model}

\subsubsection{Longitudinal (fibre-dominated) failure modes}

The material response in the longitudinal direction is assumed to be bilinear for both tensile 
and compressive loading with corresponding damage initiation stresses and fracture toughness [14]. A bilinear law (Fig. 1) is suitable for the modelling of failure in that it yields a rise in the damage parameter which resembles the exponential increase in the damage function derived from the cumulative distribution of a Weibull probability density function of fibre strength [4]. A strain-based failure initiation criterion is used where an initiation function ( $F_{11}^{T}$ and $F_{11}^{C}$ for tension and compression, respectively) is defined,

$$
\begin{aligned}
& F_{11}^{C}\left(\varepsilon_{11}\right)=\left(\frac{\varepsilon_{11}}{\varepsilon_{11}^{O C}}\right)^{2} \geq 1 \\
& F_{11}^{T}\left(\varepsilon_{11}\right)=\left(\frac{\varepsilon_{11}}{\varepsilon_{11}^{O T}}\right)^{2} \geq 1
\end{aligned}
$$

The initiation strains ( $\varepsilon_{11}^{O T}$ and $\varepsilon_{11}^{O C}$ for tension and compression, respectively) are determined by the measured strengths in the respective directions. When the initiation function reaches unity, damage begins to grow and the transmitted stress is gradually reduced to zero,

$$
\sigma_{11}^{T(C)}=\left(1-d_{11}^{T(C)}\right) \tilde{\sigma}_{11}^{T(C)}
$$

Fig. 1. Bilinear law for tension and compression (shaded area is volumetric strain energy

$$
\text { density, } \left.g_{11}^{T(C)}\right)
$$

The area under the traction-separation curve is the volumetric energy density and the damage parameter associated with loading in the fibre direction is given by

$$
d_{11}^{T(C)}\left(\varepsilon_{11}\right)=\frac{\varepsilon_{11}^{F T(C)}}{\varepsilon_{11}^{F T(C)}-\varepsilon_{11}^{O T(C)}}\left(1-\frac{\varepsilon_{11}^{O T(C)}}{\varepsilon_{11}}\right), \quad \varepsilon_{11}>\varepsilon_{11}^{O T(C)}
$$


where the failure strain, $\varepsilon_{11}^{F T(C)}$, at which net-section fracture across the element occurs, is determined by the critical energy release rate $\Gamma_{11}^{T(C)}$, longitudinal strength $X^{T(C)}$ and characteristic length $l_{c}$,

$$
\varepsilon_{11}^{F T(C)}=\frac{2 g_{11}^{T(C)}}{X^{T(C)}}=\frac{2 \Gamma_{11}^{T(C)}}{X^{T(C)} l_{c}} \rightarrow l_{c} \leq \frac{2 \Gamma_{11}^{T(C)}}{X^{T(C)} \varepsilon_{11}^{O T(C)}}
$$

An accurate measure of the characteristic length is the ratio of the elemental volume $V$ and

fracture plane $A, l_{c}=\frac{V}{A}$, where $A$ is calculated using an approach proposed in [11]. This ensures the overall energy dissipation is consistent between different mesh configurations, yielding a degree of mesh independence.

\subsubsection{Matrix failure modes}

Matrix failure is characterised by matrix cracking either longitudinally or transversely with respect to the fibre direction. Transverse (22), through-thickness (33) normal stresses, as well as shear stresses (12, 13 and 23 directions) lead to matrix-dominated failure modes. The nonlinear constitutive response of the matrix is accounted for in the present model. Following the approach presented by Puck and Schürmann [51], the orientation of the intralaminar matrix fracture plane, within an RVE, will be a function of the 3D stress state acting on that element. The orientation is determined at the onset of damage initiation and maintained in the subsequent progression of this damage mode within the RVE, as shown in Fig. 2.

Fig. 2. Coordinate system (123) rotated to the fracture plane (LNT)

The stress tensor acting on the fracture plane, $\sigma_{L N T}=\left\{\sigma_{L N}, \sigma_{N T}, \sigma_{N N}\right\}^{T}$, is rotated using the standard transformation matrix $T(\theta)$, 


$$
\begin{gathered}
\sigma_{L N T}=[T(\theta)] \sigma_{123}[T(\theta)]^{T} \\
\varepsilon_{L N T}=[T(\theta)] \varepsilon_{123}[T(\theta)]^{T} \\
T(\theta)=\left[\begin{array}{ccc}
1 & 0 & 0 \\
0 & \cos \theta & \sin \theta \\
0 & -\sin \theta & \cos \theta
\end{array}\right]
\end{gathered}
$$

Non-linear shear response of the matrix

The matrix failure initiation criterion is based on the stress state acting on the fracture plane, assuming a pre-damage linear normal stress $\sigma_{N N}$ and non-linear shear stresses $\tau_{L N(N T)}$. In this context, the non-linear shear stress profiles were defined by a cubic law, obtained using a least square fit of experimental data,

$$
\tau\left(\gamma_{i j}\right)=c_{1} \gamma_{i j}^{3}-\operatorname{sgn}\left(\gamma_{i j}\right) c_{2} \gamma_{i j}^{2}+c_{3} \gamma_{i j}
$$

where $c_{i}$ are the corresponding coefficients. The non-linear shear is expressed as the sum of an elastic and inelastic component,

$$
\gamma_{i j}=\gamma_{i j, e l}+\gamma_{i j, i n} \quad i \neq j .
$$

Prior to damage initiation, shear loading and unloading occurs along gradients defined by the initial shear modulus, $G_{i j}$, shown by paths 1 and 2 in Fig. 3 . When damage is triggered, at $\tau_{0}$, the response follows a negative tangent stiffness resulting in the softening of the secant shear modulus, with increasing applied strain, to $\left(1-d_{m a t}\right) G_{i j}$, e.g. path 3. Isotropic hardening was adopted to deal with load reversal.

Fig. 3. Non-linear shear curve with kinematic hardening

\section{Matrix damage initiation}

Puck and Schürmann's [51] criterion is widely used for predicting matrix damage behaviour. 
However, for matrix tensile failure, this criterion provides reasonable predictions only if certain relations between material strengths are satisfied. For instance, under pure transverse tension, the criterion provides correct predictions only if $Y^{T} \leq \sqrt{2} S_{23}$, where $Y^{T}$ is the transverse tensile strength. The failure initiation criterion based on Catalanotti et al. [10] overcomes this limitation and was adopted in the damage model.

If the normal stress in the fracture plane is compressive, $\sigma_{N N} \leq 0$, then

$$
F(\theta)=\left(\frac{\tau_{L N}}{S_{12}-\mu_{L N} \sigma_{N N}}\right)^{2}+\left(\frac{\tau_{N T}}{S_{23}-\mu_{N T} \sigma_{N N}}\right)^{2}
$$

and if the normal stress in the fracture plane, is tensile, $\sigma_{N N}>0$

$$
F(\theta)=\left(\frac{\sigma_{N N}}{S_{23}}\right)^{2}+\left(\frac{\tau_{L N}}{S_{12}}\right)^{2}+\left(\frac{\tau_{N T}}{S_{23}}\right)^{2}+\lambda\left(\frac{\sigma_{N N}}{S_{23}}\right)\left(\frac{\tau_{L N}}{S_{12}}\right)^{2}+\kappa\left(\frac{\sigma_{N N}}{S_{23}}\right)
$$

Where parameters $\kappa$ and $\lambda$ are given by $\kappa=\frac{S_{23}^{2}-\left(Y^{T}\right)^{2}}{S_{23} Y^{T}}, \lambda=\frac{2 \mu_{L N} S_{23}}{S_{12}}-\kappa, S_{12}$ and $S_{23}$ are the shear strengths. The transverse friction coefficients, defined in [13], are based on MohrCoulomb theory where $\mu_{N T}=-\frac{1}{\tan \left(2 \theta_{f}\right)}, S_{23}=\frac{Y_{C}}{2 \tan \left(\theta_{f}\right)}$ and $\mu_{L N}=\frac{S_{12}}{S_{23}} \mu_{N T}, Y_{C}$ is the transverse compressive strength. The fracture plane orientation, $\theta_{f}$, is typically found to be approximately $53^{\circ}$ for unidirectional composites [13] under uniaxial transverse compressive loading. For a general 3D load state, the orientation is not known a priori and is determined by the angle which maximizes the failure criteria functions of Eq. (16) or Eq. (17). Brent's algorithm [50] was used for this purpose which combines a golden section search with parabolic interpolation.

\section{Matrix damage propagation}

Matrix-dominated failure is attributed to loading in transverse compression and shear and a single damage parameter, $d_{\text {mat }}$, was used to define the degradation of the combined stress 
state, $\sigma_{r}$,

$$
\sigma_{r}=\sqrt{\left\langle\sigma_{N N}\right\rangle^{2}+\left(\tau_{N T}\right)^{2}+\left(\tau_{N L}\right)^{2}}
$$

with corresponding strain, $\varepsilon_{r}$, acting on the fracture plane $[14,52]$, defined as the vector sum of the elastic and inelastic components, $\varepsilon_{r}=\varepsilon_{r, e l}+\varepsilon_{r, \text { in }}$, where

$$
\begin{gathered}
\varepsilon_{r, e l}=\sqrt{\left\langle\varepsilon_{N N}\right\rangle^{2}+\left(\gamma_{N T}^{e l}\right)^{2}+\left(\gamma_{N L}^{e l}\right)^{2}} \\
\varepsilon_{r, i n}=\sqrt{\left(\gamma_{N T}^{i n}\right)^{2}+\left(\gamma_{N L}^{i n}\right)^{2}}
\end{gathered}
$$

and $\langle x\rangle$ is the McCauley operator, where $\langle x\rangle=\max (0, x)$. Fig. 4 shows the overall damage propagation for mixed-mode matrix damage where

$$
d_{m a t}=\frac{\varepsilon_{r}^{f}-\varepsilon_{r, i n}^{0}}{\varepsilon_{r}^{f}-\varepsilon_{r}^{0}}\left(\frac{\varepsilon_{r}^{0}-\varepsilon_{r}}{\varepsilon_{r}-\varepsilon_{r, i n}^{0}}\right)
$$

The shear stresses on the fracture plane are degraded by the matrix-dominated damage parameter $d_{\text {mat }}$,

$$
\begin{gathered}
\sigma_{L N}=\left(1-d_{m a t}\right) \tilde{\sigma}_{L N}, \\
\sigma_{N T}=\left(1-d_{m a t}\right) \tilde{\sigma}_{N T}, \\
\sigma_{N N}=\tilde{\sigma}_{N N}-d_{m a t}\left\langle\tilde{\sigma}_{N N}\right\rangle .
\end{gathered}
$$

These stresses are then transformed back to the material coordinate system to form the complete stress tensor of the damaged element.

The overall shear loading and unloading (Fig. 4) occurs along gradients defined by the initial shear modulus $\overline{G_{r}}$, given as,

$$
\overline{G_{r}}=\frac{\sigma_{r}^{0}}{\varepsilon_{r, e l}^{0}}
$$


Fig. 4. Mixed-mode matrix damage evolution

The corresponding damage parameter, $d_{m a t}$, is assumed to be a function of the resultant strain, $\varepsilon_{r}^{0}$, at damage initiation and the failure resultant strain, $\varepsilon_{r}^{f}$, which is governed by the mixed-mode critical strain energy release rate, $\Gamma_{r}$ and characteristic length, $l_{\text {mat }}$, given in the next section, where

$$
\varepsilon_{r}^{f}=\frac{2}{\sigma_{r}^{0}}\left(\frac{\Gamma_{\mathrm{r}}^{\mathrm{C}}}{l_{m a t}}-g_{0}\right)+\varepsilon_{r}^{0} .
$$

The volumetric strain energies, at damage initiation, associated with each stress component on the fracture plane, are combined using a quadratic relationship, which can be represented by the dashed region in Fig.5,

$$
g_{0}=g_{N N}^{0}\left(\frac{\left\langle\sigma_{N N}^{0}\right\rangle}{\sigma_{r}^{0}}\right)^{2}+g_{L N}^{0}\left(\frac{\tau_{L N}^{0}}{\sigma_{r}^{0}}\right)^{2}+g_{N T}^{0}\left(\frac{\tau_{N T}^{0}}{\sigma_{r}^{0}}\right)^{2}
$$

The volumetric strain energy associated with each stress component, $g_{i}^{0}$, where $i$ denotes $N N, L N$ and $N T$, is given by

$$
g_{i}^{0}=\int_{0}^{\varepsilon_{i}^{0}} \sigma_{i} d \varepsilon_{i}
$$

The critical mixed-mode strain energy release rate, $\boldsymbol{\Gamma}_{\boldsymbol{r}}^{C}$, is then given by

$$
\Gamma_{\mathrm{r}}^{\mathrm{C}}=\Gamma_{22}^{C}\left(\frac{\sigma_{N N}^{0}}{\sigma_{r}^{0}}\right)^{2}+\Gamma_{12}^{C}\left(\frac{\tau_{L N}^{0}}{\sigma_{r}^{0}}\right)^{2}+\Gamma_{23}^{C}\left(\frac{\tau_{N T}^{0}}{\sigma_{r}^{0}}\right)^{2}
$$

where $\Gamma_{i j}^{C}(i j=22,12,23)$, are the corresponding critical strain energy release rates for each stress component.

\subsection{Interlaminar damage model}

The in-built surface-based cohesive behaviour in ABAQUS/Explicit [12] was used to capture delamination using a bilinear traction-separation relationship. Failure initiation was governed by a quadratic stress criterion and delamination was propagated using a mixed-mode 
relationship proposed by Benzeggagh and Kenane [8], where the associated curve-fitting parameter, $\eta$, for the two materials used in this study, is given in Tables 2 and 3.

\subsection{Crush mechanisms}

The crushing morphology can be generally categorised by two primary failure modes, as shown in Fig. 5: (i) fragmentation mode - sequential damage of material at the microstructural level, involving interlaminar crack growth and the fracturing of laminar bundles, and (ii) splaying mode - formation of continuous fronds in combination with transverse tearing, interlaminar and longitudinal crack growth. Note too, the creation of considerable debris during the crushing process.

Fig. 5. Failure modes associated with crushing

The crashworthiness capacity can be evaluated from the specific energy absorption (SEA), $E_{s}$, defined as the energy absorbed per unit mass of material. With reference to Fig. 6 , the area under the load $(F)$ - displacement $(S)$ curve is the total energy absorbed, $W$, in the crushing process and

$$
E_{s}=\frac{W}{m}=\frac{\int F d S}{\rho V},
$$

where $\rho$ is the material density, and $V$ is the volume of crushed material.

Fig. 6. Idealised load versus displacement curve during crushing 
For the particular wedge-shaped specimen used in this study (Fig. 7) the crushed volume is given by the product of planar area, $A$, and the width of the specimen, $L$

Fig. 7. Wedge-shaped specimen

$$
A=\left\{\begin{array}{cc}
0.5 \frac{S^{2}}{\tan \theta}, & S \leq S_{u} \\
0.5 \frac{S_{u}^{2}}{\tan \theta}+\left(S-S_{u}\right) T, & S_{u}<S \leq S_{t}
\end{array}\right.
$$

Where $S_{u}$ and $S_{t}$ are the lengths of the upper part and the total wedge respectively, and $T$ is the thickness of the specimen. In addition, the peak load , $P$, is considered one of the critical design parameters which should be minimised to prevent severe injury to passengers [27]. Consequently, an ideal crashworthy component achieves the maximum SEA with minimum peak load. To compare specimens with different geometries (width and thickness), the peak stress $S$ is used,

$$
S=P / A_{\text {cross }}
$$

Where $A_{\text {cross }}$ is the full cross sectional area of the specimen.

\section{Model validation}

\subsection{Experimental set-up}

\subsubsection{Test set-up and specimens}

A series of experimental results taken from $[21,25,26]$ were used to validate the damage model and assess the model's capacity to predict the crushing process. The finite element model of the experimental set-up is shown in Fig. 8, where quasi-static crushing tests were performed using a hydraulic testing machine at a constant crosshead displacement rate of 
$6 \mathrm{~mm} / \mathrm{min}$. The non-clamped length was set to $30 \mathrm{~mm}$ for the crossply laminate specimens and $10 \mathrm{~mm}$ for the thinner unidirectional (UD) laminate specimens.

Fig. 8. Finite element model of test set-up

A summary of specimen geometries and materials is given in Table 1. Specimens A to D were made from T700/M21 UD plies, with different lay-ups and triggers (chamfer-angles $20^{\circ}$ and $45^{\circ}$ ). Specimen E was made from T700/MTM57 UD plies, with a stacking sequence of $\left[\left(90^{\circ}\right)_{8}\right]$

Table 1. Specimen configurations

\subsubsection{Material Properties}

Material properties for T700/M21 were obtained from [26] and those for T700/MTM57 from a related reference [21]. These are given in Table 2 and Table 3 where it is noted that the coefficients, $c_{i}(i=1,2,3)$, for the non-linear shear response were obtained using a least square fit of experimental data presented in [49] and [21] respectively. $\Gamma_{j j}^{d i r}$ denotes the longitudinal $(j j=11)$ and transverse $(j j=22)$ intralaminar fracture toughness in tension $(\operatorname{dir}=T)$ and compression $(\operatorname{dir}=C)$ These properties were obtained using compact tension and compact compression specimens as described in [34] and based on ASTM standard tests [2]. $G_{I}$ and $G_{I I}$ are the interlaminar fracture toughness for mode I, obtained from ASTM test method D5528-01 [1], and mode II, obtained from a 4-point bend end notch flexure test[54]. A three-point bend, end notch flexure test method is also currently under development by ASTM [3]. The density of T700/M21 and T700/MTM57 is $1.5 \mathrm{~g} / \mathrm{cm}^{3}$ and $1.52 \mathrm{~g} / \mathrm{cm}^{3}$ respectively. 
Table 2. Material properties of T700/M21 for numerical simulation [26]

Table 3. Material properties of T700/MTM57 for numerical simulation [21]

\subsection{Finite element modelling}

\subsubsection{Model definition}

Virtual wedge specimens were created in ABAQUS/Explicit 6.11. The non-clamped part was meshed using an approximate element size of $0.25 \mathrm{~mm}$ in the longitudinal and transverse directions as shown in Fig. 9, while for the clamped part the mesh size was approximately $2 \mathrm{~mm}$. In order for C3D8R elements to capture the bending behaviour, three elements through the thickness of each ply were used. To suppress spurious energy modes, an enhanced stiffness-based hourglass and distortion control were employed [12].

The surface based cohesive behaviour was employed to capture delamination between adjacent plies. A general contact algorithm was utilised to generate a contact force between contact surfaces. 'Hard' contact conditions were defined between the platen and the plies as well as adjacent plies. The platen was modelled as an analytical rigid surface. The friction coefficients were set to 0.2 for T700/M21 and 0.3 for T700/MTM57 [21]. The computational loading speed was fixed at $1 \mathrm{~m} / \mathrm{s}$ to reduce the CPU time whilst ensuring that the quality of the results was not affected by inertial effects. Selective mass scaling, which only scaled elements whose stable time increment was below 1e-07 s, was also employed during the crushing process to achieve a reasonable run time. Models were run on a Windows Cluster with 16 CPUs with a run time of between 6 and 8 hours, depending on the specimen type. 


\subsubsection{Element deletion strategy}

A challenge which is faced in the modelling of composite crushing concerns the handling of highly distorted elements. The current damage model accounts for different damage modes and there are often instances when considerable matrix damage has been accumulated but fibre-dominated damage has yet to be activated. This would imply that an element may still be able to support subsequent loading and deleting an element on the basis of accumulated damage in one mode may be premature, reducing the accuracy of the simulation. On the other hand, the failure in one mode may result in a high level of element distortion which may lead to the solution aborting. Increasing the robustness of the solution process involves balancing these two considerations.

An efficient strategy for determining when element deletion is likely to have to be invoked, due to element distortion, is to track the value of the determinant of the Jacobian operator (det J) [6] and delete the element if this value approaches zero. As $\mathbf{J}$ is not available directly from ABAQUS/VUMAT, and adding this calculation to the subroutine would incur an additional computational cost, the strategy adopted was to interrogate the determinant of the deformation gradient ( $\operatorname{det} \mathbf{F}$ ) which is available directly from ABAQUS. Det $\mathbf{F}$ yields the ratio of the deformed, $V$, and undeformed, $V_{0}$, volume of an element,

$$
\operatorname{det} \mathbf{F}=\frac{V}{V_{0}}
$$

and provides a reasonable indication of element distortion. The overall element distortion criterion was subsequently based on both the fibre-dominated longitudinal damage parameter, $d_{11}^{T(C)}$, and limits on det $\mathbf{F}$ for tracking large changes in element volume,

$$
\text { Delete element if }\left\{\begin{array}{c}
d_{11}^{T(C)}>0.99 \\
\operatorname{det} \mathbf{F}<0.8 \text { or } \operatorname{det} \mathbf{F}>1.6
\end{array}\right.
$$

The limits on det $\mathbf{F}$ are user defined and the quoted values were found to yield good results. 


\section{Results and discussion}

Specimens with different stacking sequences (A-C in Table 1) but with the same chamfer angle of $20^{\circ}$ were modelled to determine the predictive capability of the damage model in capturing the experimentally-observed variations in their crush behaviour, reported in [25, 26]. Specimen D, with a larger chamfer angle of $45^{\circ}$, was included to compare the trigger effect. In addition, specimen $\mathrm{E}$ was manufactured with a different resin.

\subsection{Lay-up}

\subsection{1 $\left[\left(0^{\circ} / 90^{\circ}\right)_{4}\right]_{s}$ with a $20^{\circ}$ chamfer angle}

The numerical results in Fig. 9a achieved excellent qualitative correlation with the experimental crushing morphologies. The global force-displacement response (Fig. 9b) further confirms the quantitative accuracy of the present damage model. The numerical oscillations are the result of element deletion laws invoked as part of the solution. At the beginning of the crushing process (stage 1), damage was primarily in the form of local fragmentation due to intralaminar damage. From stage 1 to stage 2, the reaction force increased gradually to the peak load at which point the entire uniform cross-section of the crush element came in contact with the platen (displacement, $S=1.5 \mathrm{~mm}$ ). Afterwards, extensive delamination initiated with a splaying mode (stage 3), leading to a sudden drop in the reaction force. The specimen underwent some bending as the chamfer was being consumed. From stage 4 to 6 , mixed-mode damage with fragmentation in the middle plies and splaying in the outer plies was observed. Internal debris was created and acted like a 'wedge' in driving delamination. 
Fig. 9. (a) Experimental morphologies [25] and numerical matrix damage contour; (b) forcedisplacement curve of crushing test on $\left[\left(0^{\circ} / 90^{\circ}\right)_{4}\right]_{\mathrm{s}}$ specimen; (c) energy dissipationdisplacement curves

The evolution of energy dissipated through various mechanisms during crushing is illustrated in Fig. 9c, Fig. 10d, Fig. 11c, Fig. 12c and Fig. 14c for all specimens tested, verifying the energy balance relationship between external work done and energy absorbed. In all of these cases, the majority of energy was dissipated through intralaminar damage, followed by friction between the crushing platen and specimen, and delamination. The small amount of viscous energy dissipated is due to the use of the Bulk Viscosity Method [37] to damp out spurious oscillations in explicit dynamic simulations. Most of the energy in this crushing event was dissipated at the initial stage (i.e. displacement from $0 \mathrm{~mm}$ to $2 \mathrm{~mm}$ in Fig. 9c) of the crushing process, when the reaction force increased dramatically as the chamfer was gradually consumed. Hence the energy dissipated was primarily due to fragmentation rather than splaying.

\subsection{2 $\left[0^{\circ}\right]_{8}$ with a $20^{\circ}$ chamfer angle}

Fig. 10a shows good agreement between the morphology observed from experimental and numerical results. The predicted matrix-dominated damage contours indicate extensive fragmentation at the initial loading stages. The longitudinal compressive damage and delamination can be observed in Fig. 10b. The global crush response correlates well with the experimental results where the initial contact response and maximum force were all predicted with good accuracy (Fig. 10c). 
Fig. 10. (a) Experimental morphologies [25] and numerical matrix-dominated damage contours; (b) left -longitudinal compressive damage; right - delamination; (c) forcedisplacement curve of crushing test on $\left[0^{\circ}\right]_{8}$ specimen; (d) energy dissipationdisplacement curves

\subsection{3 $\left[90^{\circ}\right]_{8}$ with a $20^{\circ}$ chamfer angle}

Brittle fracture and accompanying debris were well predicted by the numerical model shown in Fig. 11a. This typical matrix-dominated damage is primarily associated with transverse and shear loading, resulting in plasticity and the formation of cracks in the matrix material. The force-displacement curve in Fig. 11b was consistent with experimental data involving the initial stiffness, peak load and damage growth. The observed increase in stiffness, after $1 \mathrm{~mm}$ displacement (experimental and numerical results), is most probably due to the comparatively small level of splaying observed beyond initial brittle fracture such that a substantial cross section of the specimen is still mostly intact and able to transmit load. In contrast to the unidirectional specimen $\left[0^{\circ}\right]_{8}$, the peak load of the $\left[90^{\circ}\right]_{8}$ specimen was much lower at only $1.7 \mathrm{kN}$ compared to $6.7 \mathrm{kN}$. As expected, having the fibres aligned to the loading axis in the unidirectional specimen allowed for greater energy dissipation. This is also confirmed by a comparison of the energy dissipation curves in Fig. 10d and Fig. 11c.

Fig. 11. (a)Experimental morphologies [25] and numerical matrix damage contours; (b) force-displacement curve of crushing test on $\left[90^{\circ}\right]_{8}$ specimen; (c) energy dissipationdisplacement curves 


\subsection{Trigger}

\subsection{1 $\left[\left(0^{\circ} \% 0^{\circ}\right)_{4}\right]_{s}$ with a $45^{\circ}$ chamfer angle}

A $45^{\circ}$ chamfer angle was employed to investigate the trigger effect. In terms of morphologies, all major damage forms were well captured by the model, Fig. 12a, and the force-displacement curve demonstrates excellent correlation, particularly in capturing the initial stiffness and peak load. Static I and II curves denote two identical experimental tests under quasi-static loading. With a larger chamfer angle, more material is consumed before the platen reaches the entire cross-section, which can be deduced from a comparison of displacements at peak load in Fig. 9b (1.5mm) and Fig. 12b (3.2mm).

Fig. 12. (a) Experimental morphologies [26] and numerical matrix damage contours; (b) force-displacement curve of crushing test on $\left[\left(0^{\circ} / 90^{\circ}\right)_{4}\right]_{\mathrm{s}}$ specimen with $45^{\circ}$ chamfer; (c) energy dissipation- displacement curves

\subsection{2 $\left[\left(0^{\circ} / 90^{\circ}\right)_{4}\right]_{s}$ without trigger}

With reference to the $\left[\left(0^{\circ} / 90^{\circ}\right) 4\right]_{s}$ specimen with a $20^{\circ}$ chamfer angle (specimen A), a similar specimen without a trigger was modelled. Fig. 13a shows the sequence of failure in the specimen, in which extensive intralaminar damage occurred suddenly. This catastrophic failure is also reflected in the high value of peak loading, Fig. 13b, compared to Specimen A.

Fig. 13. (a) Numerical matrix damage contours; (b) force-displacement curve of crushing test on $\left[\left(0^{\circ} / 90^{\circ}\right)_{4}\right]_{\mathrm{s}}$ specimen without trigger 


\subsection{Material}

\subsection{1 $\left[90^{\circ}\right]_{8}$ with a $10^{\circ}$ chamfer angle}

This test was performed on a $\left[90^{\circ}\right]_{8}$ specimen made of T700/MTM57. In Fig. 14a, both the experimental result and the numerical model displayed brittle fracture. The constitutive response obtained from the numerical simulation shows excellent agreement with experimental results (Fig. 14b).

Fig. 14. (a) Experimental morphologies [21] and numerical matrix damage contours; (b) force-displacement curve of crushing test on $\left[90^{\circ}\right]_{8}$ specimen with $10^{\circ}$ chamfer; (c) energy dissipation- displacement curves

\subsection{Discussion}

\subsubsection{Energy absorption predictions}

Fig. 15a illustrates the SEA results from experimental and numerical tests. For case D, with two specimen results reported, an average value was used. Numerical data matched the experimental values well, which demonstrates the predictive capability of the damage model in capturing the SEA during crushing. These SEA values, for thermoset composites, are comparable with results found in literature (ranging from $20 \mathrm{~J} / \mathrm{g}$ to $100 \mathrm{~J} / \mathrm{g}$ ) dealing with other specimen geometries [17]. The peak stress was found to have a similar high level of correlation as shown in Fig. 15b. The effect of particular parameters on the energy absorption and peak stress of composite material, under crushing load, is summarized below. 
Fig. 15. (a) Comparison of SEA; (b) Comparison of peak stress

Lay-up

With the same chamfer angle, the unidirectional specimen $\left[0^{\circ}\right]_{8}$ shows the highest experimentally determined SEA of $127 \mathrm{~J} / \mathrm{g}$, followed by the crossply specimen $\left[\left(0^{\circ} / 90^{\circ}\right)_{4}\right]_{\mathrm{s}}$ at $105.5 \mathrm{~J} / \mathrm{g}$ and $\left[90^{\circ}\right]_{8}$ at $45.7 \mathrm{~J} / \mathrm{g}$. In addition, the $\left[0^{\circ}\right]_{8}$ lay-up exhibited the highest peak stress, while layup $\left[90^{\circ}\right]_{8}$ lead to the lowest peak stress. From these simple test specimens, a crossply laminate is shown to offer a good compromise between a low and high SEA associated with the $\left[90^{\circ}\right]_{8}$ and $\left[0^{\circ}\right]_{8}$ respectively, and a high $\left[0^{\circ}\right]_{8}$ and low $\left[90^{\circ}\right]_{8}$ peak stress. This indicates that an energy absorption profile can be partially tailored through stacking sequence design in addition to the design of energy-absorbing structural configurations.

Fig. 16 shows the results of a crush simulation of a $\left[\left(45^{\circ} /-45^{\circ}\right)_{4}\right]_{\mathrm{s}}$ with a $20^{\circ}$ trigger chamfer. The peak load and energy dissipation history is shown to vary from the other layups investigated. The SEA for this specimen was $58.4 \mathrm{~J} / \mathrm{g}$ and achieved a peak stress of 73.3MPa.These results are consistent with those obtained for the unidirectional, transverse and cross-ply lay-ups presented in this paper and confirm the damage model's ability to capture variations in the crushing response resulting from changes to the lay-up of a laminated structure.

Fig. 16. (a) Numerical matrix damage contour; (b) force-displacement curve of crushing test on $\left[\left(45^{\circ} /-45^{\circ}\right)_{4}\right]_{\mathrm{s}}$ specimen

Trigger Type

The comparison between specimens $\mathrm{A}$ and $\mathrm{D}$ shows that the chamfer angle variation investigated $\left(20^{\circ}\right.$ and $\left.45^{\circ}\right)$ did not result in a large variation in the magnitude of SEA. The 
SEA value for a chamfer angle of $45^{\circ}$ was slightly less than that of the $20^{\circ}$ specimen. From the morphologies in Fig. 9a and Fig. 12a, it can be seen that the failure mechanisms of A and $\mathrm{D}$ are quite similar with fragmentation in the middle and splaying of the outer plies. With reference to Fig. 15b, it would seem that a larger chamfer angle decreases the observed and predicted peak stress.

\subsubsection{Friction}

The role of friction between the crushing surface and the metallic base, which influences the accumulation of debris and wedge formation, plays an important role in the crush response, as does friction between composite surfaces. A study was conducted to investigate the influence of friction between the loading platen and the crushing surface. With reference to Fig. 17, a range of friction coefficients were used to simulate the crushing response of Specimen A. As expected, with increasing friction, there is more resistance to the crushed surface sliding across the platen leading to an increase in apparent stiffness, peak load and energy dissipated. A friction coefficient of 0.2 yielded excellent correlation with experimental results.

Fig. 17. (a) Experimental morphologies and numerical matrix damage contour; (b) force-displacement curve of crushing test on $\left[\left(0^{\circ} / 90^{\circ}\right) 4\right]_{\mathrm{s}}-20^{\circ}$ specimen with different friction coefficients

\subsubsection{In-built Hashin model}

ABAQUS has a built-in progressive damage model based on Hashin's criteria [22] which can only be used with continuum shell elements (SC8R). Simulation of the $\left[\left(0^{\circ} / 90^{\circ}\right)_{4}\right]_{\mathrm{s}}$ specimen, with a $20^{\circ}$ chamfer angle, was performed using these criteria, for comparison with the 
proposed damage model. Three elements through the thickness of each ply were also used. To suppress spurious energy modes, an enhanced stiffness-based hourglass control was employed. Fig. 18a shows a poor correlation between the experimental morphologies and numerical results obtained from the ABAQUS built-in model. It is noted that numerical results show extensive splaying with some ply buckling, associated with the degradation in material stiffness. The results in Fig. 18b reveal a lower initial stiffness and peak load. Energy curves in Fig. 18c indicate that the total energy absorbed by the specimen was approximately $4 \mathrm{~J}$ lower than that predicted by the proposed model (c.f. $7 \mathrm{~J}$ at a displacement of $4 \mathrm{~mm})$. The SEA for this specimen was $83.1 \mathrm{~J} / \mathrm{g}$ (20\% lower than that predicted by the proposed model, $105.5 \mathrm{~J} / \mathrm{g}$ ). The simulation terminated prematurely due to excessive element distortion. The default element deletion strategy in ABAQUS is based on the value of the damage parameters only and does not consider element distortion.

There are several fundamental differences between the Hashin damage model provided by ABAQUS and the proposed progressive damage model. These differences are summarised below:

a) The implemented Hashin's criteria assume that the behaviour of the undamaged material is linearly elastic, while the proposed model takes into account the non-linear shear behaviour of the matrix.

b) The ABAQUS composites damage model predicts damage initiation and damage evolution solely on plane stress components, ignoring the contribution of transverse stress components. In contrast, the proposed model predicts constituent failure using the full 3D stress state.

c) The characteristic length given by ABAQUS is the cubic root of the volume of the element, which is only accurate when elements have aspect ratios close to unity and crack planes are assumed to evolve perpendicular to the mid-plane of the element. 
The proposed model provides an accurate estimate of the fracture plane area, which can assume any orientation within an element. The characteristic length is calculated by dividing the volume of the finite element by this area.

Overall, the proposed damage model presented in this paper achieved significant improvements in terms of morphologies, load response and energy absorption predictions compared to the ABAQUS built-in model.

Fig. 18. (a) Delamination damage contour and Hashin's compressive matrix damage contour; (b) force-displacement curve of crushing test on $\left[\left(0^{\circ} / 90^{\circ}\right) 4\right]_{\mathrm{s}}-20^{\circ}$ specimen

\section{Conclusions}

A composite damage model that accounts for both intralaminar (matrix and fibre damage) and interlaminar (delamination) damage was presented which has shown a high degree of capability in predicting crushing behaviour of composite laminates. This 3D model included an updated damage initiation criterion, robust unloading/reloading mechanism, a unified matrix damage law and a sound element deletion strategy. Through published experimental data, the crushing tests successfully demonstrated that the model can capture:

- Both the qualitative and quantitative aspects of the intralaminar and interlaminar crushing damage for a range of stacking sequences, triggers and materials.

- Crashworthiness features (specific energy absorption and peak stress) with a high degree of accuracy.

- The contribution of each damage mechanism to the overall energy absorption during crushing. 
This was achieved without the need to calibrate the material parameters, required as input parameters for the damage model, which were obtained from reliable literature sources.

\section{Acknowledgement}

The corresponding author would like to acknowledge the financial support of Bombardier and the Royal Academy of Engineering. The authors would also like to gratefully acknowledge the funding from the Queen's University Belfast/China Scholarship Council (QUB/CSC) PhD Scholarship and the support from the Research Computing Team at QUB in accessing the HPC facilities. 


\section{References}

[1] ASTM, Standard Test Method for Mode I Interlaminar Fracture Toughness of Unidirectional Fiber-Reinforced Polymer Matrix Composites, American Society for Testing and Materials, D5528-01, West Conshohocken, PA, 2001.

[2] ASTM, Standard Test Method for Translaminar Fracture Toughness of Laminated Polymer Matrix Composite Materials, E1922-04, ASTM International, Conshohocken, PA, 2004.

[3] ASTM, New Test Method for Determination of the Mode II Interlaminar Fracture Toughness of Unidirectional Fiber Reinforced Polymer Matrix Composites Using the End-Notched Flexure (ENF) Test, WK22949, ASTM International, Conshohocken, PA, 2010.

[4] E.J. Barbero, Introduction to Composite Materials Design, 2nd edition ed, CRC Press, Boca Raton FL, USA, 2011.

[5] S. Barre, T. Chotard, and M. Benzeggagh, Comparative study of strain rate effects on mechanical properties of glass fibre-reinforced thermoset matrix composite, Compos. Part. A-appl. S 27 (1996), pp. 1169-1181.

[6] K.-J. Bathe, Finite element procedures, ed, Klaus-Jurgen Bathe, 2006.

[7] G. Belingardi, M. Cavatorta, and R. Duella, Material characterization of a compositefoam sandwich for the front structure of a high speed train, Compos. Struct. 61 (2003), pp. 13-25.

[8] M.L. Benzeggagh, and M. Kenane, Measurement of mixed-mode delamination fracture toughness of unidirectional glass/epoxy composites with mixed-mode bending apparatus, Composites science and technology 56 (1996), pp. 439-449.

[9] C. Bisagni, G. Di Pietro, L. Fraschini, and D. Terletti, Progressive crushing of fiberreinforced composite structural components of a Formula One racing car, Compos. Struct. 68 (2005), pp. 491-503.

[10] G. Catalanotti, P. Camanho, and A. Marques, Three-dimensional failure criteria for fiber-reinforced laminates, Compos. Struct. (2012)

[11] L.N. Chiu, B.G. Falzon, and R. Boman, A Continuum Damage Mechanics Model for the Analysis of the Crashworthiness of Composite Structures: A work in progress, in Proceedings of the 15th Australian Aeronautical Conference, Melbourne, 2013. 
[12] Dassault-Systems, ABAQUS Documentation 6.11, SIMULIA, 2011.

[13] M.V. Donadon, L. Iannucci, B.G. Falzon, J.M. Hodgkinson, and S.F.M. de Almeida, A progressive failure model for composite laminates subjected to low velocity impact damage, Comput. Struct. 86 (2008), pp. 1232-1252.

[14] A. Faggiani, and B.G. Falzon, Predicting low-velocity impact damage on a stiffened composite panel, Composites Part A: Applied Science and Manufacturing 41 (2010), pp. 737-749.

[15] B.G. Falzon, and P. Apruzzese, Numerical analysis of intralaminar failure mechanisms in composite structures. Part I: FE implementation, Compos. Struct. 93 (2011), pp. 1039-1046.

[16] B.G. Falzon, and P. Apruzzese, Numerical analysis of intralaminar failure mechanisms in composite structures. Part II: Applications, Compos. Struct. 93 (2011), pp. 1047-1053.

[17] P. Feraboli, Development of a corrugated test specimen for composite materials energy absorption, J. Compos. Mater. 42 (2008), pp. 229-256.

[18] D. Fleming, Modelling composite crushing initiation using a cohesive element formulation, INT. J. CRASHWORTHINES 16 (2011), pp. 475-485.

[19] F. Garattoni, Crashworthiness and composite materials: development of an experimental test method for the energy absorption determination and implementation of the relative numerical model, $\mathrm{PhD}$ Thesis, University of Bologna (2011)

[20] L. Grauers, R. Olsson, and R. Gutkin, Energy absorption and damage mechanisms in progressive crushing of corrugated NCF laminates: Fractographic analysis, Compos. Struct. 110 (2014), pp. 110-117.

[21] R. Gutkin, Modelling Compressive Damage in CFRP: Combining Friction with Damage, in the 19th International Conference on Composite Materials, Montreal, Canada, 2013.

[22] Z. Hashin, Failure criteria for unidirectional fiber composites, Journal of applied mechanics 47 (1980), pp. 329-334.

[23] J. Huang, and X. Wang, On a new crush trigger for energy absorption of composite tubes, INT. J. CRASHWORTHINES 15 (2010), pp. 625-634.

[24] W. Hufenbach, R. Bohm, M. Thieme, A. Winkler, E. Mader, J. Rausch, and M. Schade, Polypropylene/glass fibre 3D-textile reinforced composites for automotive applications, Materials \& Design 32 (2011), pp. 1468-1476. 
[25] H.A. Israr, S. Rivallant, and J.J. Barrau, Experimental investigation on mean crushing stress characterization of carbon-epoxy plies under compressive crushing mode, Compos. Struct. 96 (2013), pp. 357-364.

[26] H.A. Israr, S. Rivallant, C. Bouvet, and J.J. Barrau, Finite element simulation of $0^{\circ} / 90^{\circ} \mathrm{CFRP}$ laminated plates subjected to crushing using a free-face-crushing concept, Compos. Part. A-appl. S 62 (2014), pp. 16-25.

[27] G.C. Jacob, J.F. Fellers, S. Simunovic, and J.M. Starbuck, Energy absorption in polymer composites for automotive crashworthiness, J. Compos. Mater. 36 (2002), pp. 813-850.

[28] A.F. Johnson, and M. David, Failure mechanisms in energy-absorbing composite structures, Philosophical Magazine 90 (2010), pp. 4245-4261.

[29] M. Joosten, S. Dutton, D. Kelly, and R. Thomson, Experimental and numerical investigation of the crushing response of an open section composite energy absorbing element, Compos. Struct. 93 (2011), pp. 682-689.

[30] L.M. Kachanov, Introduction to Continuum Damage Mechanics, Boston: Martinus Nijhoff Publishers (1986)

[31] Z. Kazanc1, and K.-J. Bathe, Crushing and crashing of tubes with implicit time integration, Int. J. Impact. Eng. 42 (2012), pp. 80-88.

[32] M. Kiani, H. Shiozaki, and K. Motoyama, Using Experimental Data to Improve Crash Modeling for Composite Materials, in Composite Materials and Joining Technologies for Composites, Volume 7, E. Patterson, D. Backman and G. Cloud eds., Springer New York, 2013, pp. 215-226.

[33] J.-S. Kim, H.-J. Yoon, and K.-B. Shin, A study on crushing behaviors of composite circular tubes with different reinforcing fibers, Int J Impact Eng 38 (2011), pp. 198207.

[34] M.J. Laffan, S.T. Pinho, P. Robinson, L. Iannucci, and A.J. McMillan, Measurement of the fracture toughness associated with the longitudinal fibre compressive failure mode of laminated composites, Compos. Part. A-appl. S 43 (2012), pp. 1930-1938.

[35] S.T. Lau, M. Said, and M.Y. Yaakob, On the effect of geometrical designs and failure modes in composite axial crushing: A literature review, Compos. Struct. 94 (2012), pp. 803-812.

[36] J. Lemaitre, and J.L. Chaboche, Mechanics of solid materials, ed, Cambridge University Press, Cambridge, UK, 1990. 
[37] L. Maheo, V. Grolleau, and G. Rio, Numerical damping of spurious oscillations: a comparison between the bulk viscosity method and the explicit dissipative TchamwaWielgosz scheme, Computational Mechanics 51 (2013), pp. 109-128.

[38] P. Mangalgiri, Composite materials for aerospace applications, B. Mater. Sci. 22 (1999), pp. 657-664.

[39] C. McGregor, R. Vaziri, and X. Xiao, Finite element modelling of the progressive crushing of braided composite tubes under axial impact, Int. J. Impact. Eng. 37 (2010), pp. 662-672.

[40] A. Najafi, D. Huang, F. Abdi, and M. Rais-Rohani, Test Validation on the Energy Absorption Behavior of Composite Tubes with Different Ply Architectures, in SAMPE 2012 Conference, Baltimore, MD, 2012.

[41] A. Najafi, D. Huang, M. Rais-Rohani, F. Abdi, and C. Heydari, Simulation of Crushing Process in Composite Tubes, in 51st AIAA/ASME/ASCE/AHS/ASC Structures, Structural Dynamics, and Materials Conference, Orlando,FL, 2010.

[42] S. Palanivelu, W.V. Paepegem, J. Degrieck, J. Vantomme, D. Kakogiannis, J.V. Ackeren, D.V. Hemelrijck, and J. Wastiels, Crushing and energy absorption performance of different geometrical shapes of small-scale glass/polyester composite tubes under quasi-static loading conditions, Compos. Struct. 93 (2011), pp. 992-1007.

[43] S. Palanivelu, W. Van Paepegem, J. Degrieck, D. Kakogiannis, J. Van Ackeren, D. Van Hemelrijck, J. Wastiels, and J. Vantomme, Parametric study of crushing parameters and failure patterns of pultruded composite tubes using cohesive elements and seam, Part I: Central delamination and triggering modelling, Polym. Test. 29 (2010), pp. 729-741.

[44] S. Palanivelu, W. Van Paepegem, J. Degrieck, J. Van Ackeren, D. Kakogiannis, D. Van Hemelrijck, J. Wastiels, and J. Vantomme, Experimental study on the axial crushing behaviour of pultruded composite tubes, Polym. Test. 29 (2010), pp. 224234.

[45] S. Palanivelu, W. Van Paepegem, J. Degrieck, J. Van Ackeren, D. Kakogiannis, J. Wastiels, D. Van Hemelrijck, and J. Vantomme, Parametric study of crushing parameters and failure patterns of pultruded composite tubes using cohesive elements and seam: Part II - Multiple delaminations and initial geometric imperfections, Polym. Test. 29 (2010), pp. 803-814. 
[46] L. Pickett, and V. Dayal, Effect of tube geometry and ply-angle on energy absorption of a circular glass/epoxy crush tube - A numerical study, Compos. Part. B-eng. 43 (2012), pp. 2960-2967.

[47] S. Pinho, P. Camanho, and M. De Moura, Numerical simulation of the crushing process of composite materials, INT. J. CRASHWORTHINES 9 (2004), pp. 263-276.

[48] S. Pinho, L. Iannucci, and P. Robinson, Physically based failure models and criteria for laminated fibre-reinforced composites with emphasis on fibre kinking. Part II: FE implementation, Compos. Part. A-appl. S 37 (2006), pp. 766-777.

[49] M. Preetamkumar, L. Gilles, L. Pierre, and G. Ana-cristina, Validation of Intralaminar Behaviour of the Laminated Composites by Damage Mesomodel, in 50th AIAA/ASME/ASCE/AHS/ASC Structures, Structural Dynamics, and Materials Conference, American Institute of Aeronautics and Astronautics, 2009.

[50] W.H. Press, Numerical recipes in Fortran 77: the art of scientific computing, ed, Vol. 1, Cambridge university press, 1992.

[51] A. Puck, and H. Schürmann, Failure analysis of FRP laminates by means of physically based phenomenological models, Compos. Sci. Technol. 58 (1998), pp. 1045-1067.

[52] L. Raimondo, L. Iannucci, P. Robinson, and P. Curtis, A progressive failure model for mesh-size-independent FE analysis of composite laminates subject to low-velocity impact damage, Compos. Sci. Technol. 72 (2012), pp. 624-632.

[53] S. Ramakrishna, H. Hamada, Z. Maekawa, and H. Sato, Energy absorption behavior of carbon-fiber-reinforced thermoplastic composite tubes, J. Thermoplast. Compos 8 (1995), pp. 323-344.

[54] C. Schuecker, and B.D. Davidson, Evaluation of the accuracy of the four-point bend end-notched flexure test for mode II delamination toughness determination, Compos. Sci. Technol. 60 (2000), pp. 2137-2146.

[55] SIMULIA, Simulating composites crush and crash events using ABAQUS, 50th AIAA/ASME/ASCE/AHS/ASC Structures, Structural Dynamics, and Materials Conference (2009)

[56] V.S. Sokolinsky, K.C. Indermuehle, and J.A. Hurtado, Numerical simulation of the crushing process of a corrugated composite plate, Compos. Part. A-appl. S 42 (2011), pp. 1119-1126. 
[57] A. Turon, P.P. Camanho, J. Costa, and J. Renart, Accurate simulation of delamination growth under mixed-mode loading using cohesive elements: Definition of interlaminar strengths and elastic stiffness, Compos. Struct. 92 (2010), pp. 1857-1864.

[58] W. Van Paepegem, I. De Baere, E. Lamkanfi, and J. Degrieck, Monitoring quasistatic and cyclic fatigue damage in fibre-reinforced plastics by Poisson's ratio evolution, Int. J. Fatigue. 32 (2010), pp. 184-196.

[59] B. Vieille, V.M. Casado, and C. Bouvet, Influence of matrix toughness and ductility on the compression-after-impact behavior of woven-ply thermoplastic- and thermosetting-composites: A comparative study, Compos. Struct. 110 (2014), pp. 207-218.

[60] X. Xiao, C. McGregor, R. Vaziri, and A. Poursartip, Progress in braided composite tube crush simulation, Int. J. Impact. Eng. 36 (2009), pp. 711-719. 


\section{Figures}

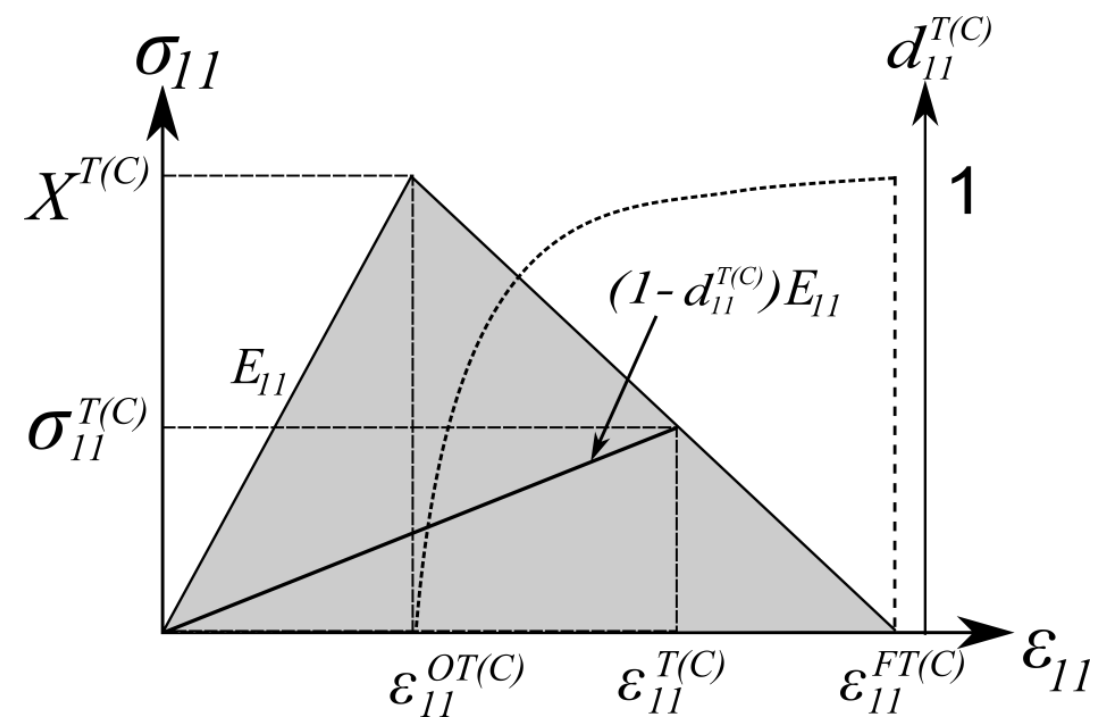

Fig. 1. Bilinear law for tension and compression (shaded area is volumetric strain energy density $g_{11}^{T(C)}$ ) 


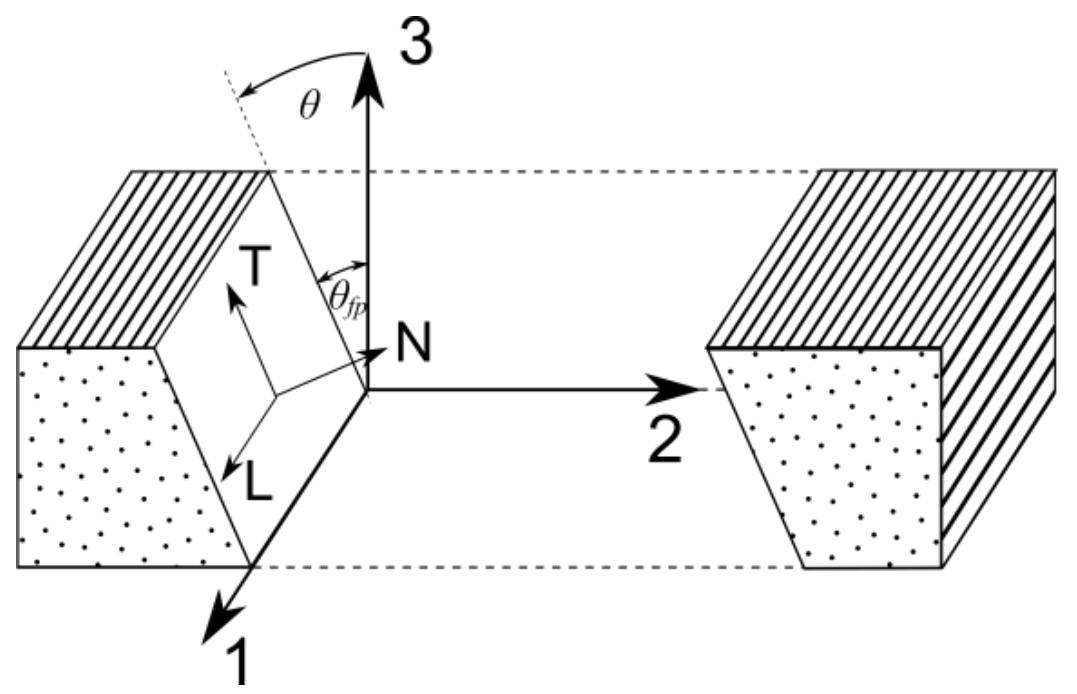

Fig. 2. Coordinate system (123) rotated to the fracture plane system (LNT) 


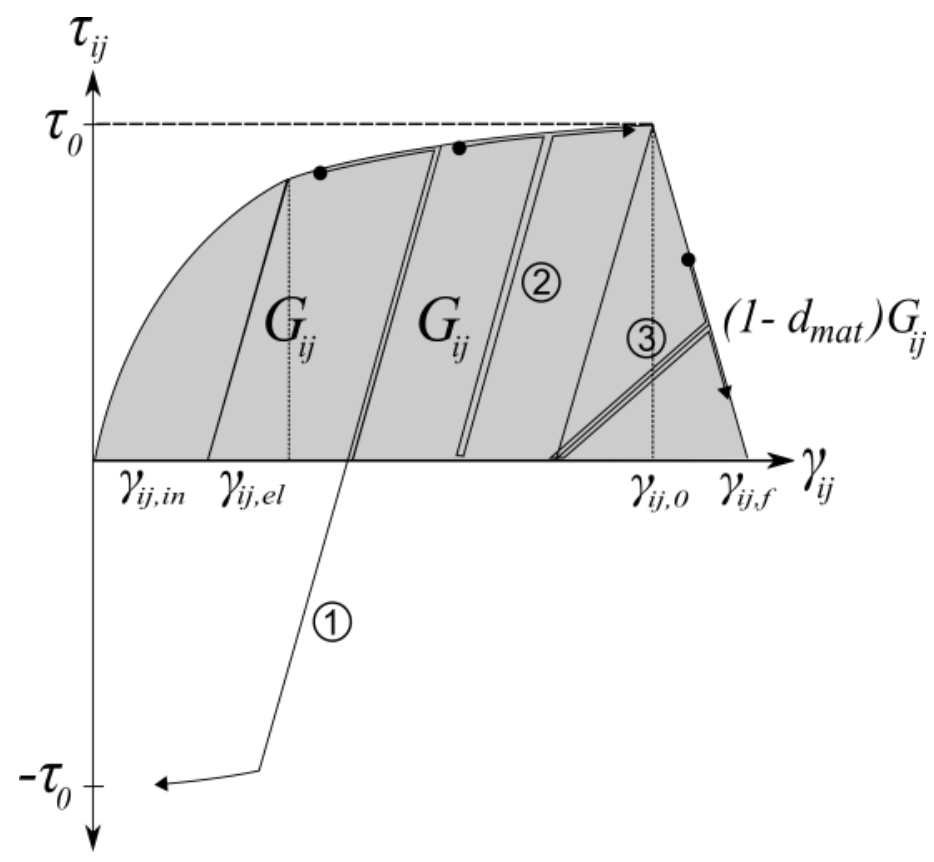

Fig. 3. Non-linear shear curve with kinematic hardening 


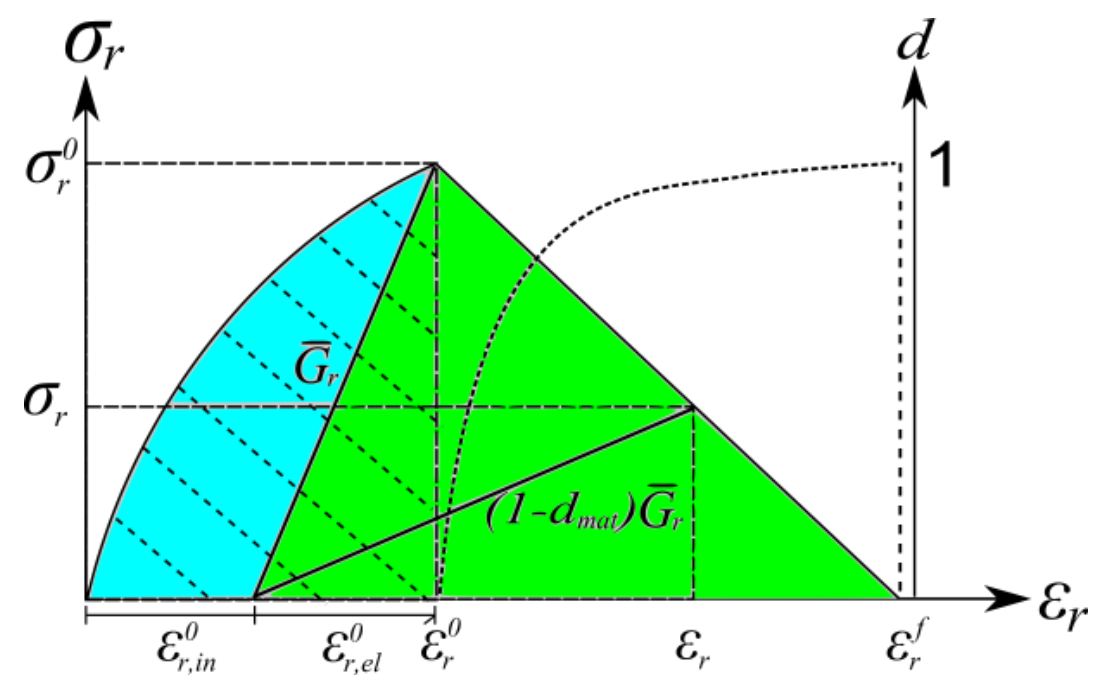

Fig. 4. Mixed-mode matrix damage evolution 


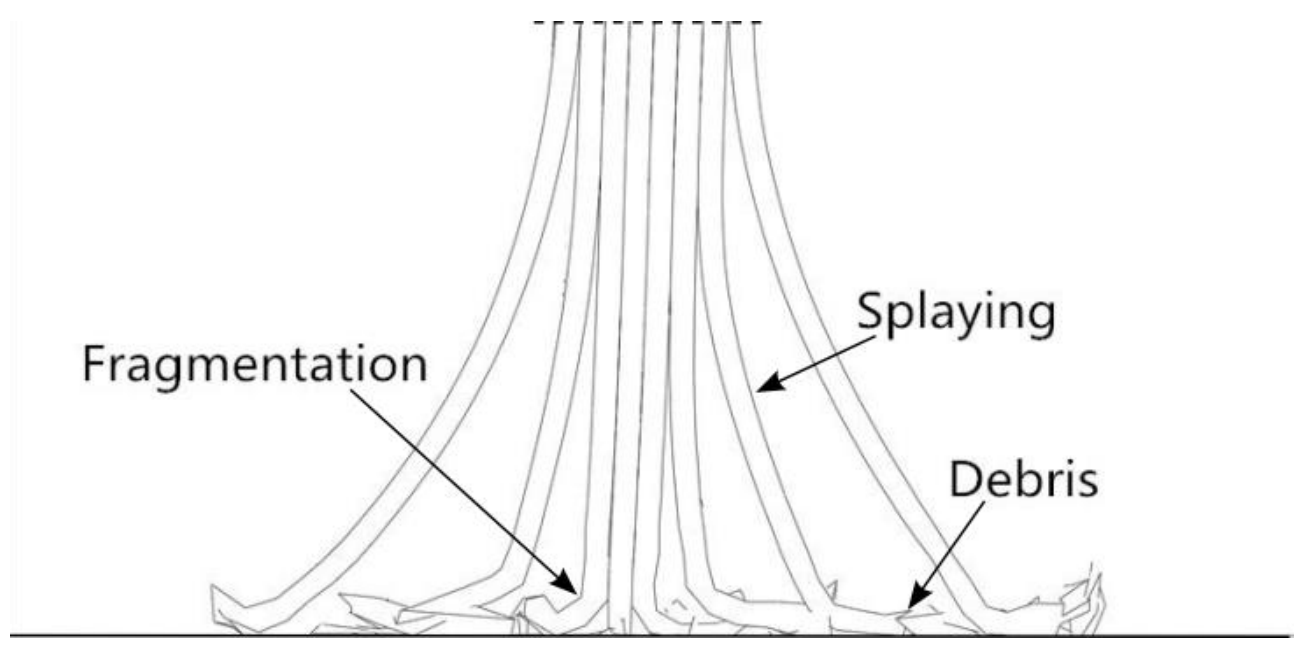

Fig. 5. Failure modes associated with crushing 


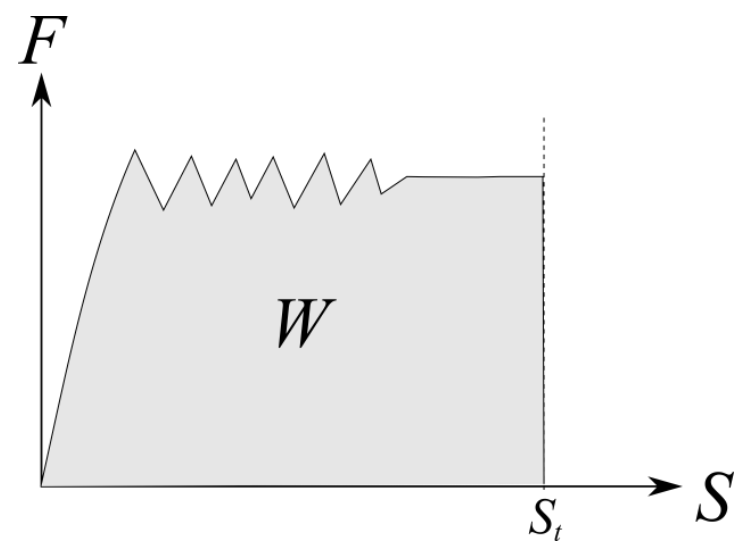

Fig. 6. Idealised load versus displacement curve during crushing 


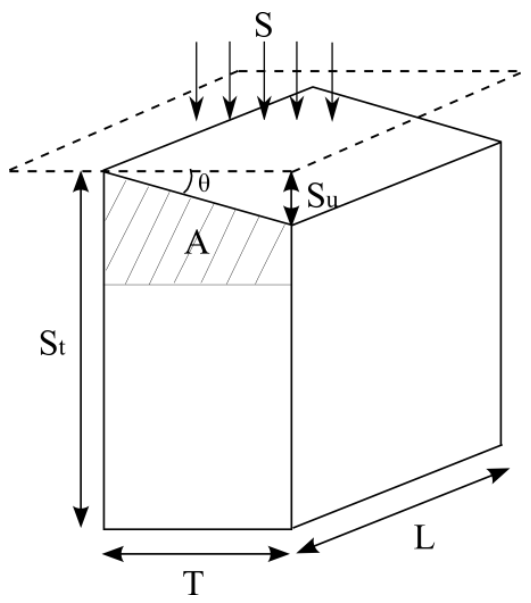

Fig. 7. Wedge shape specimen 


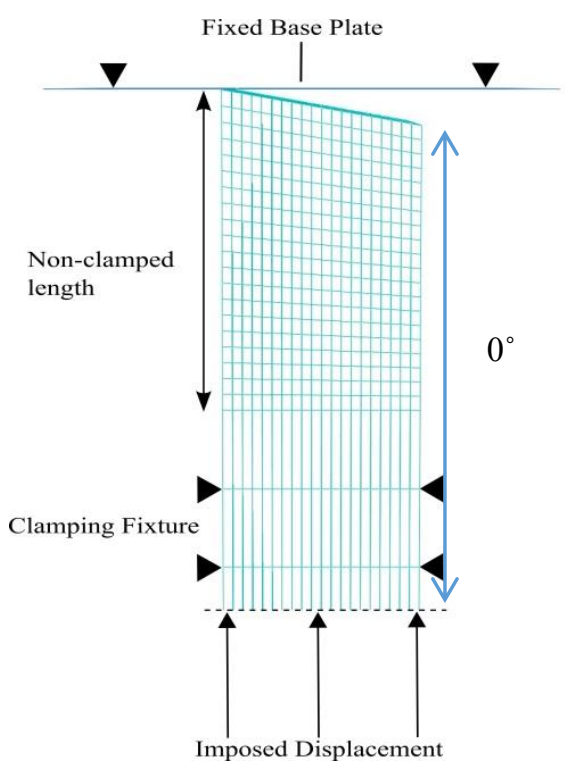

Fig. 8. Finite element model of test set-up 

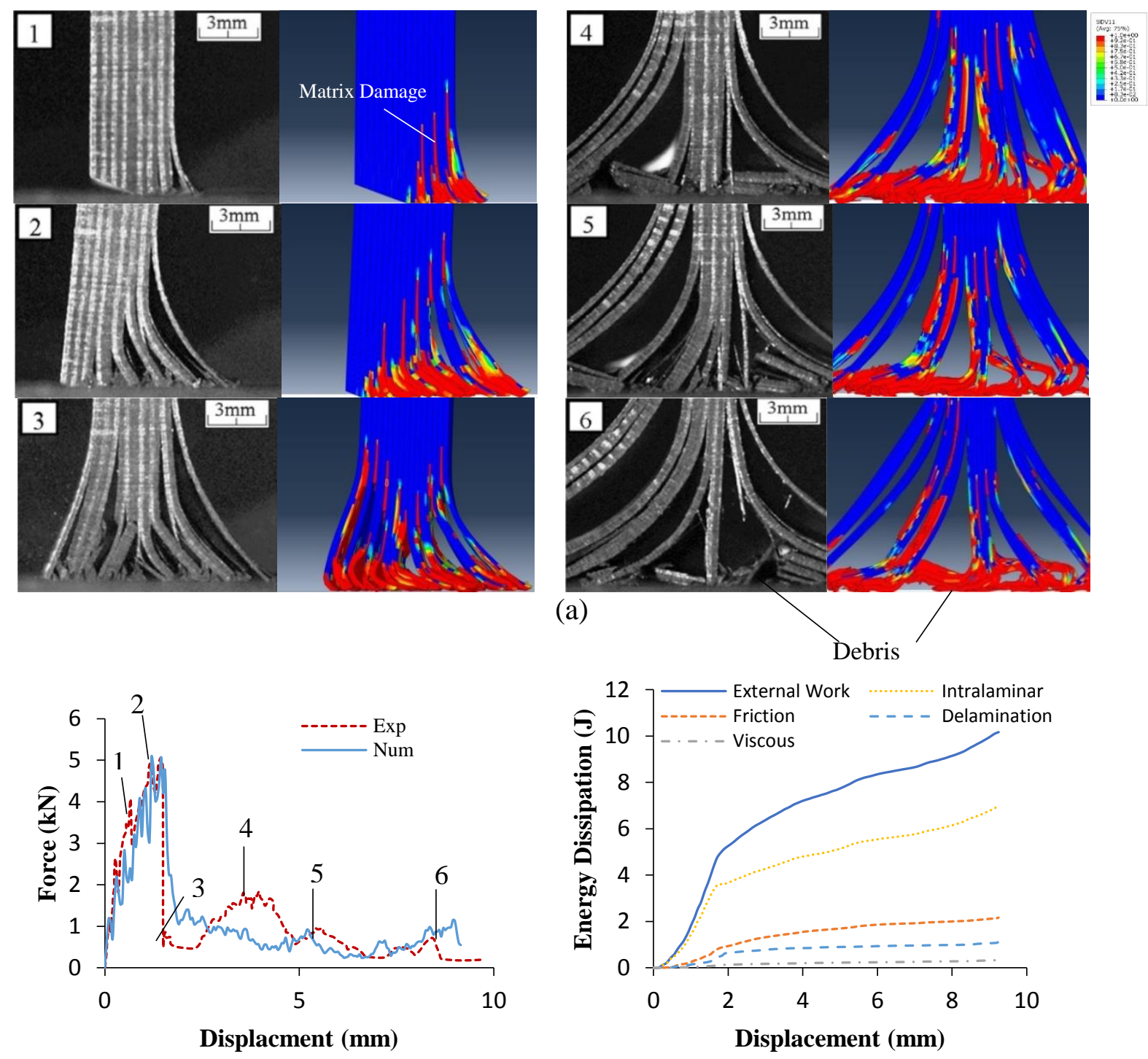

(b)

(c)

Fig. 9. (a) Experimental morphologies [25] and numerical matrix damage contour; (b) forcedisplacement curve of crushing test on $\left[\left(0^{\circ} / 90^{\circ}\right)_{4}\right]_{\mathrm{s}}$ specimen ; (c) energy dissipationdisplacement curves 

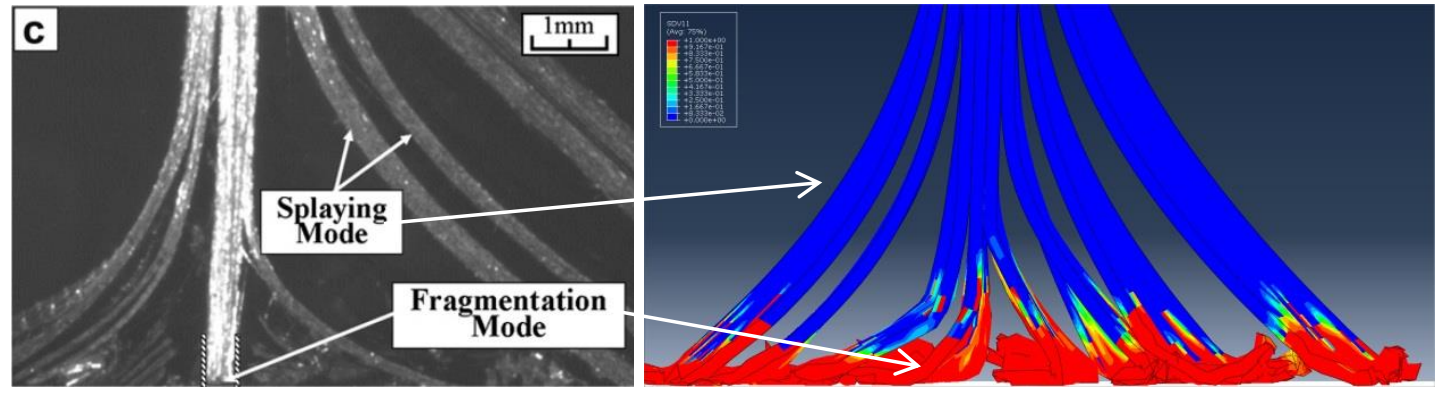

(a)
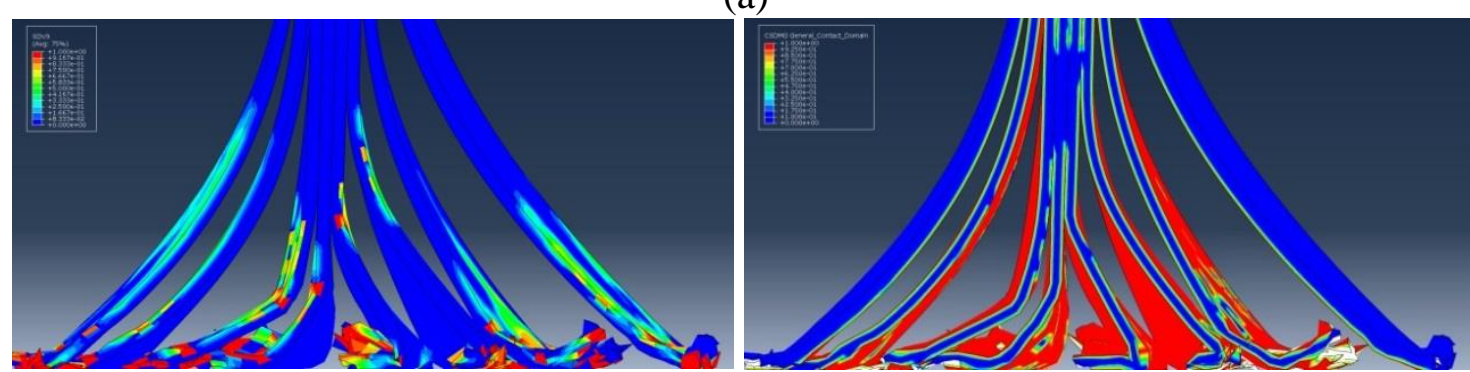

(b)

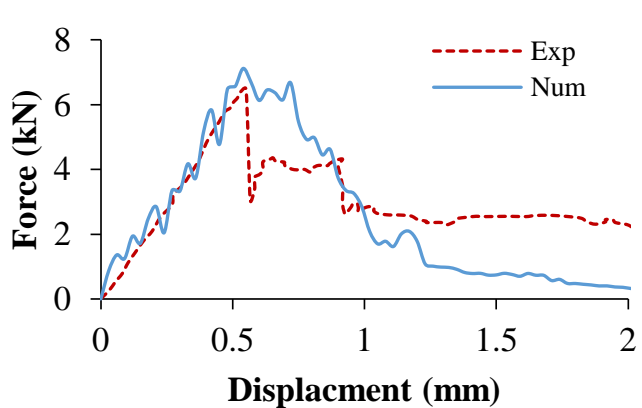

(c)

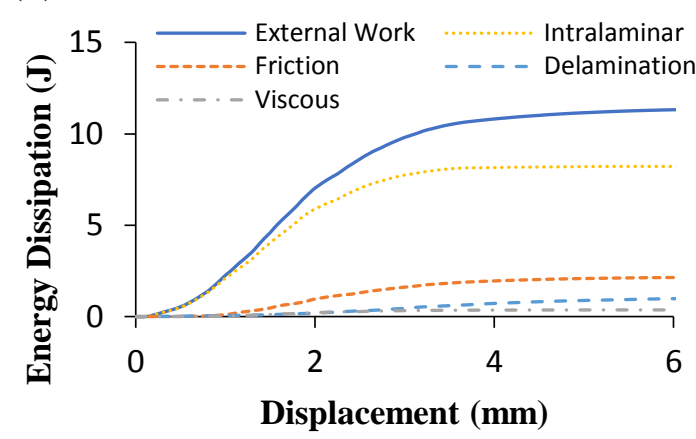

(d)

Fig. 10. (a) Experimental morphologies [25] and numerical matrix-dominated damage contours; (b) left -longitudinal compressive damage; right - delamination; (c) forcedisplacement curve of crushing Test on $\left[0^{\circ}\right]_{8}$ spceimen; (d) energy dissipationdisplacement curves 

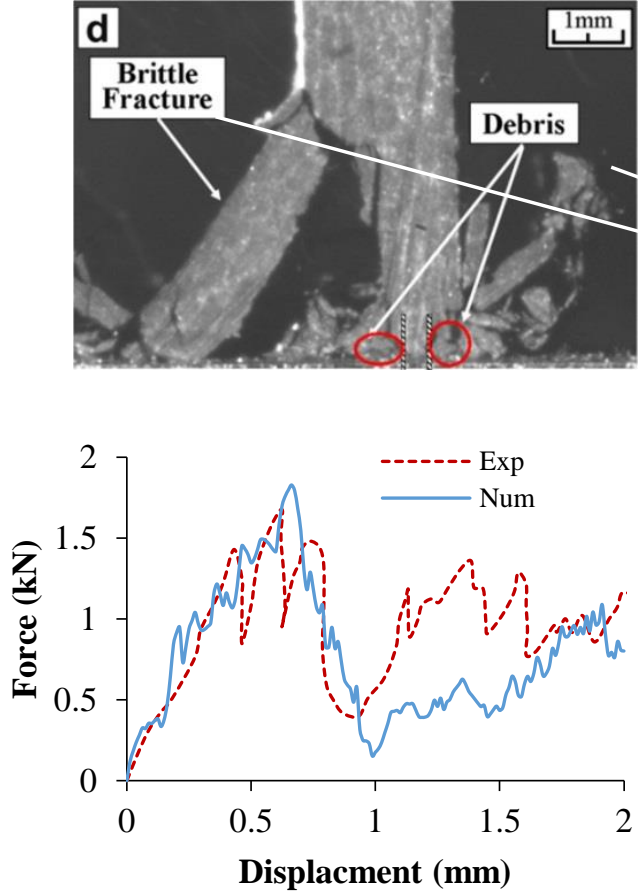

(b)

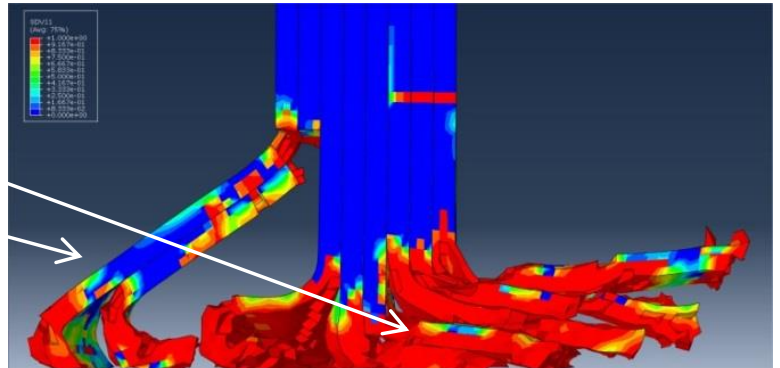

(a)

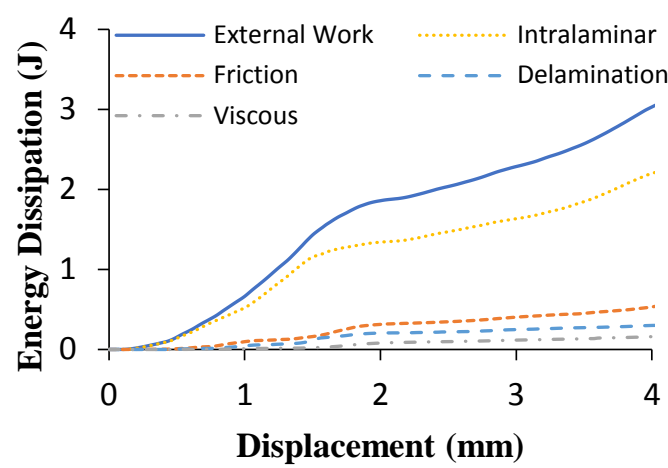

(c)

Fig. 11. (a)Experimental morphologies [25] and numerical matrix damage contours;

(b) force-displacement curve of crushing test on $\left[90^{\circ}\right]_{8}$ specimen; (c) energy dissipationdisplacement curves 

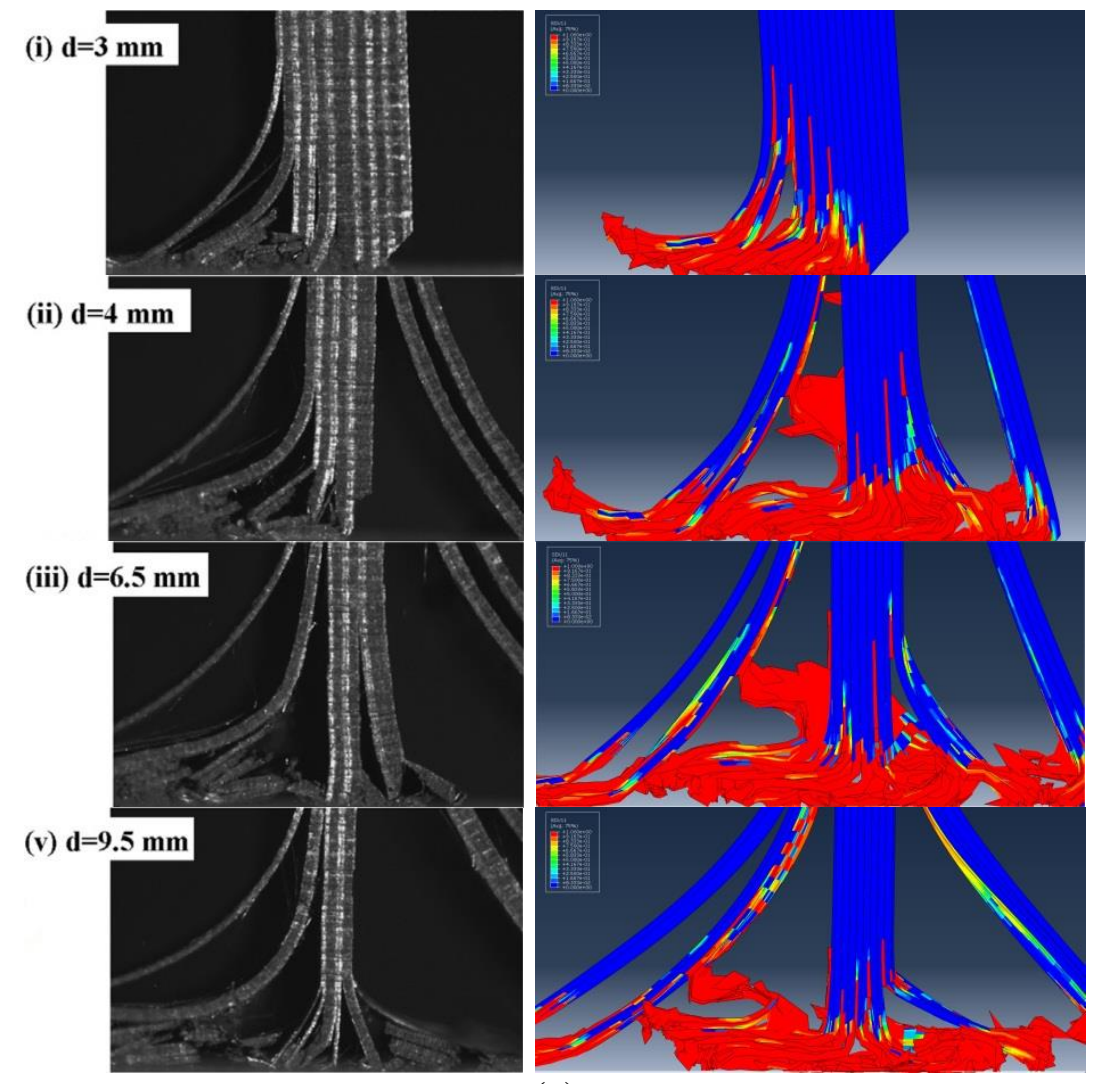

(a)

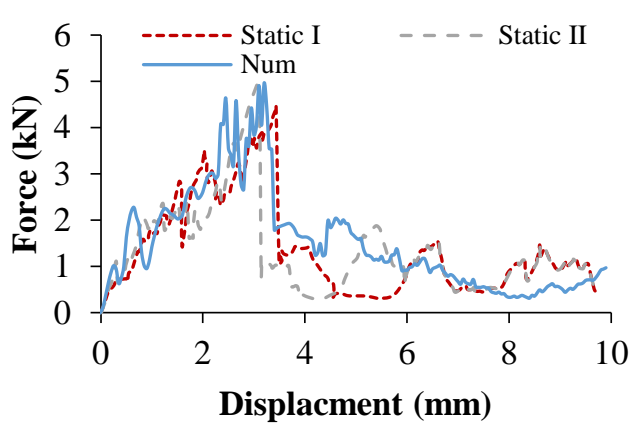

(b)

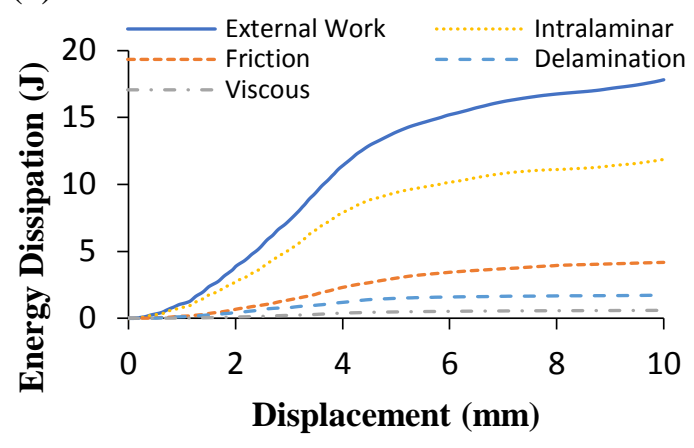

(c)

Fig. 12. (a) Experimental morphologies [26] and numerical matrix damage contours;

(b) force-displacement curve of crushing test on $\left[\left(0^{\circ} / 90^{\circ}\right)_{4}\right]_{\mathrm{s}}$ specimen with $45^{\circ}$ chamfer;

(c) energy dissipation- displacement curves 

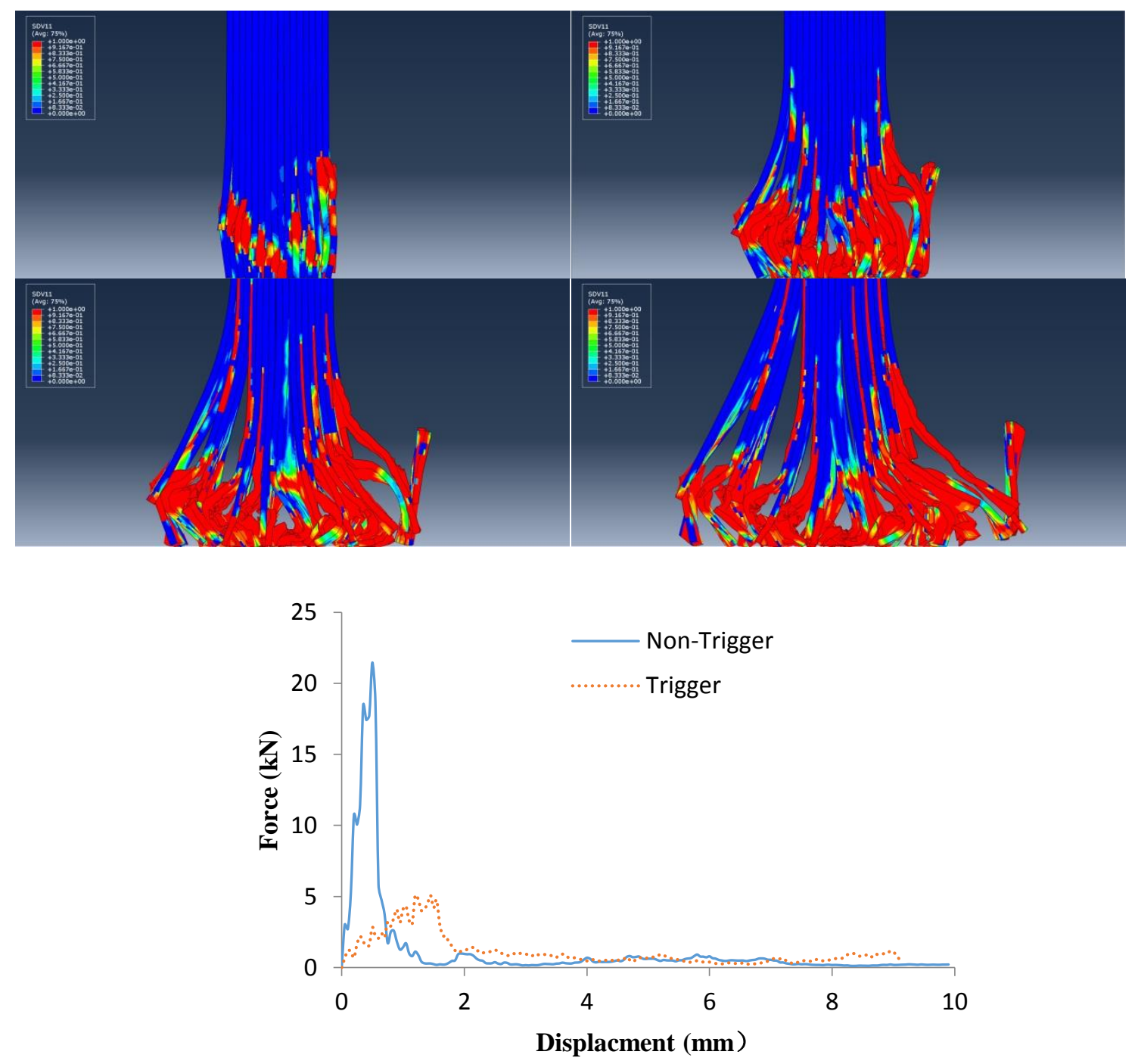

Fig. 13. (a) Numerical matrix damage contours; (b) force-displacement curve of crushing test on $\left[\left(0^{\circ} / 90^{\circ}\right) 4\right] \mathrm{s}$ specimen without trigger compared with trigger $20^{\circ}$ 

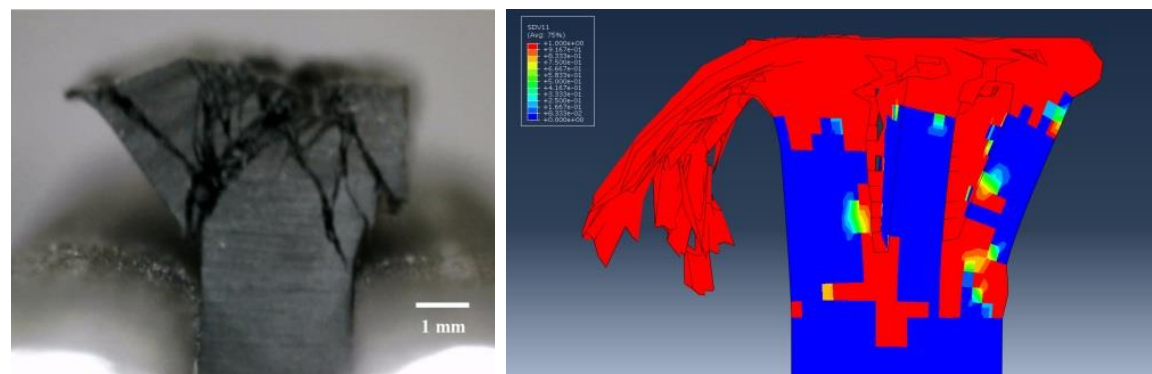

(a)

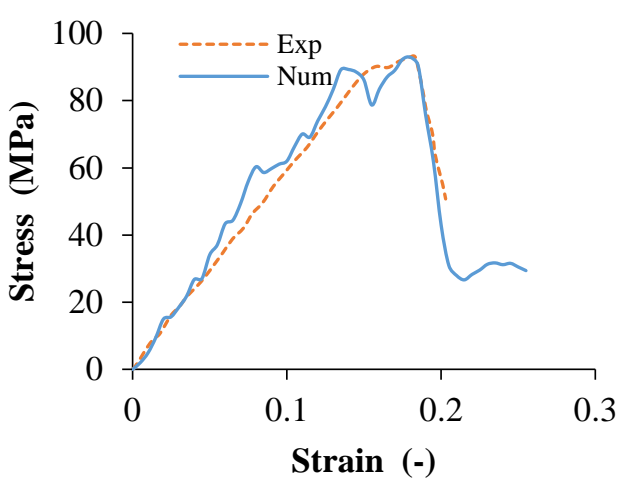

(b)

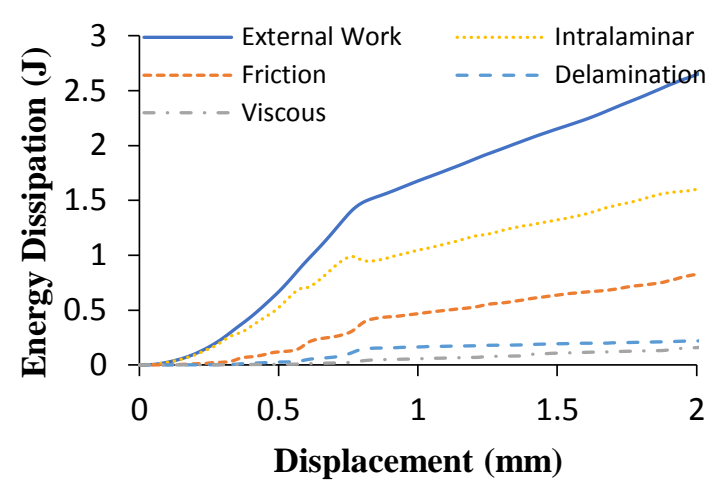

(c)

Fig. 14. (a) Experimental morphologies [21] and numerical matrix damage contours;

(b) force-displacement curve of crushing test on $\left[90^{\circ}\right]_{8}$ specimen with $10^{\circ}$ chamfer; (c) energy dissipation- displacement curves 


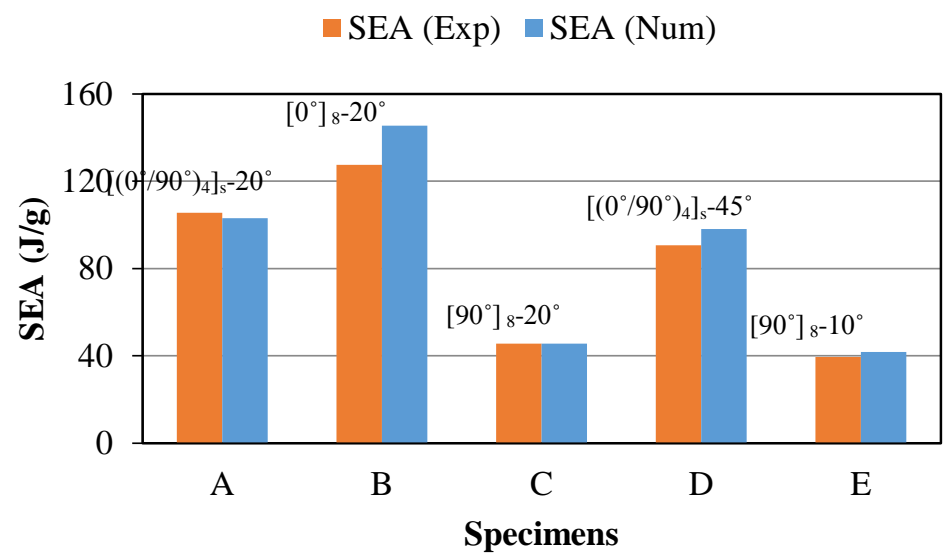

(a)

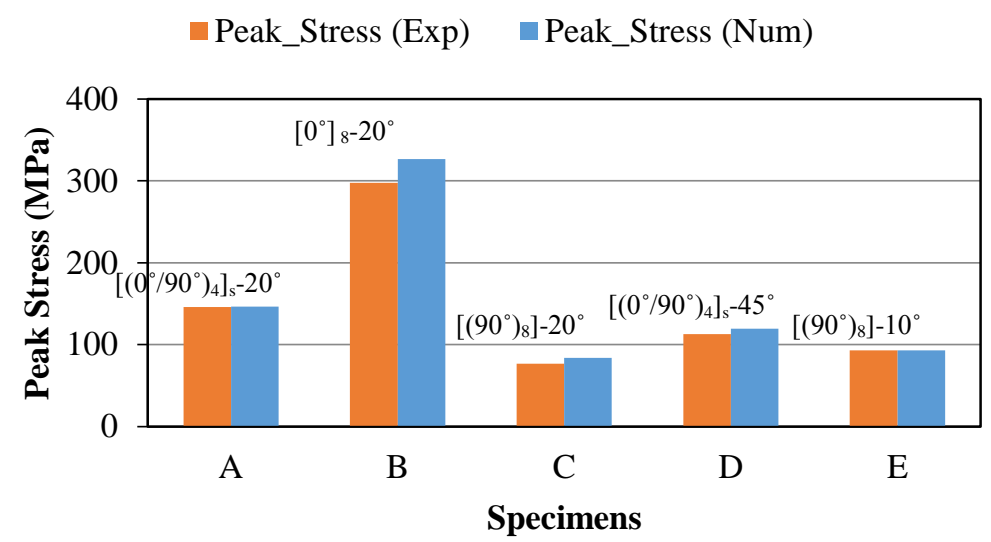

(b)

Fig. 15. (a) Comparison of SEA; (b) Comparison of peak stress 


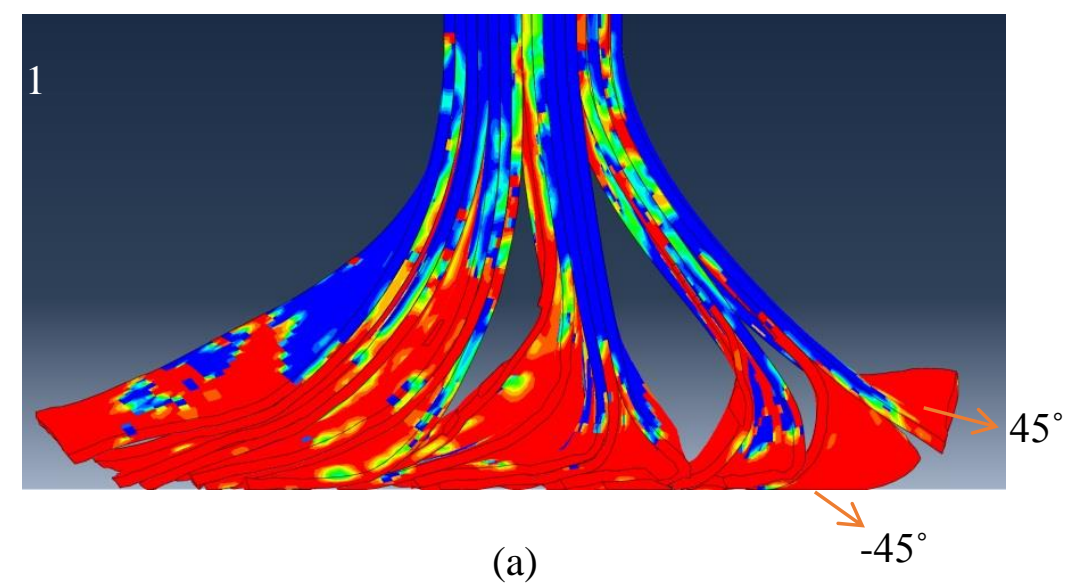

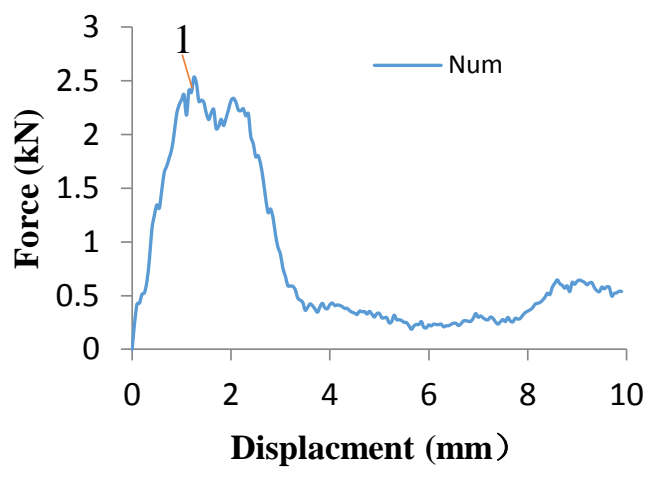

(b)

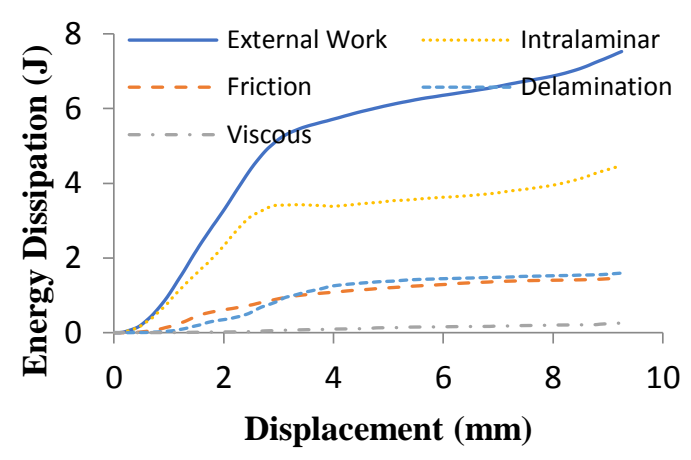

(c)

Fig. 16. (a) Numerical matrix damage contour; (b) force-displacement curve of crushing test on $\left[\left(45^{\circ} /-45^{\circ}\right)_{4}\right]_{\mathrm{s}}$ specimen; (c) energy dissipation- displacement curves 


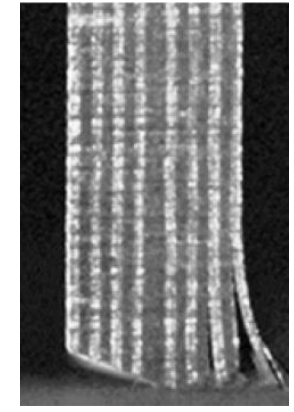

$\operatorname{Exp}$

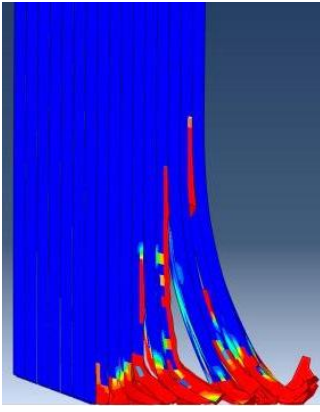

$\mathrm{f}=0.05$

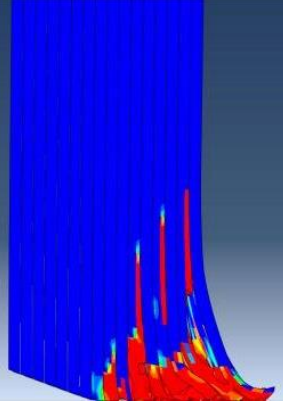

$\mathrm{f}=0.15$

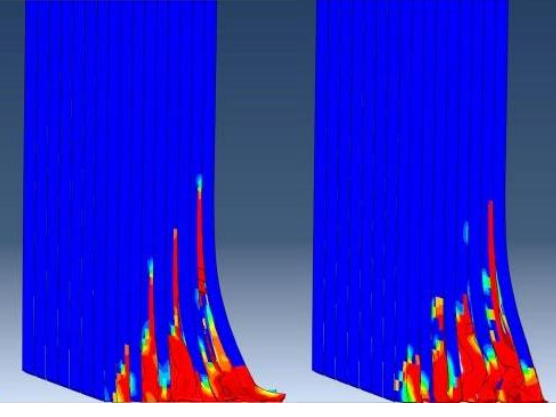

(a)

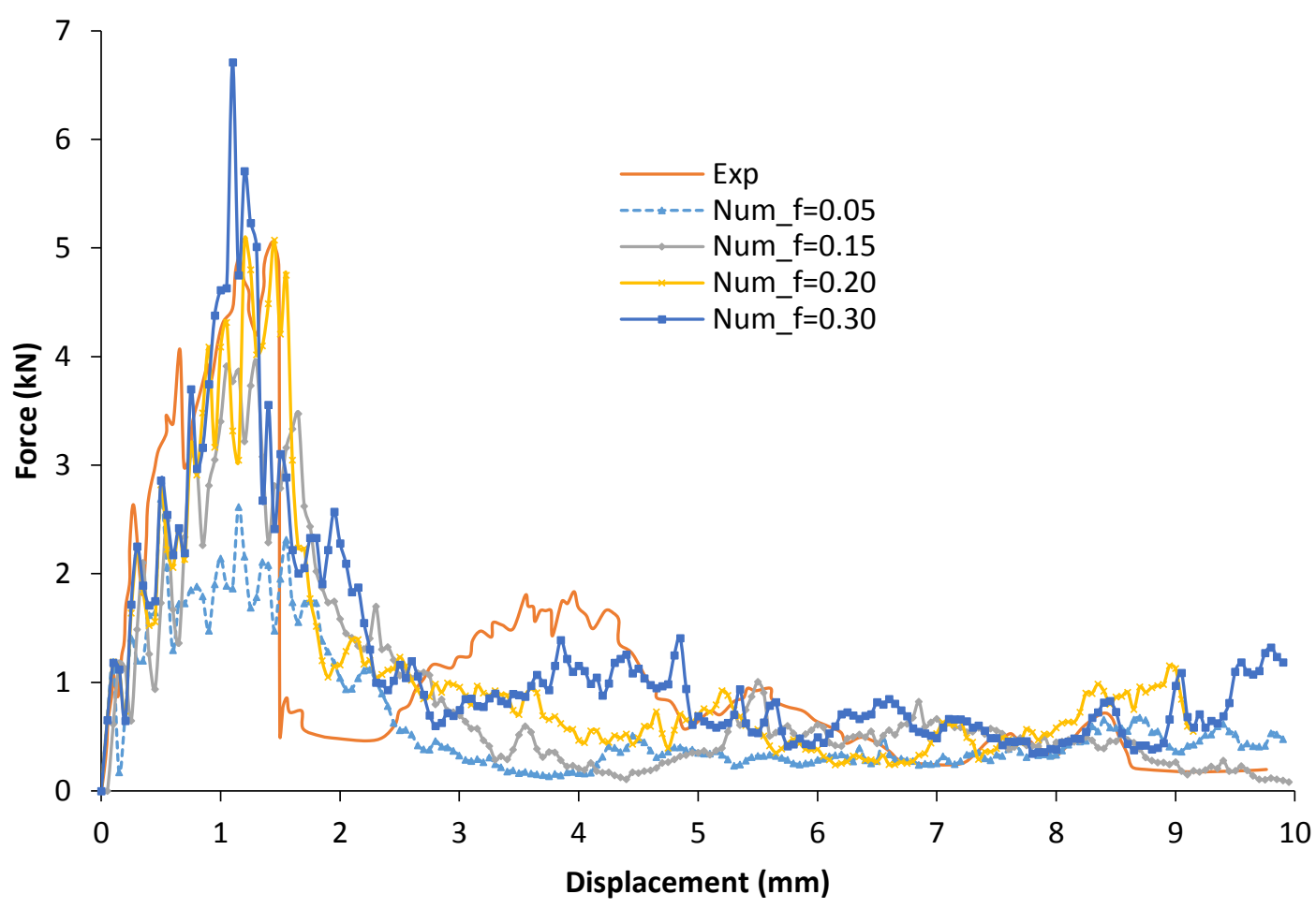

(b)

Fig. 17. (a) Experimental morphologies and numerical matrix damage contour; (b) force-displacement curve of crushing test on $\left[\left(0^{\circ} / 90^{\circ}\right)_{4}\right]_{\mathrm{s}}-20^{\circ}$ specimen with different friction coefficients 

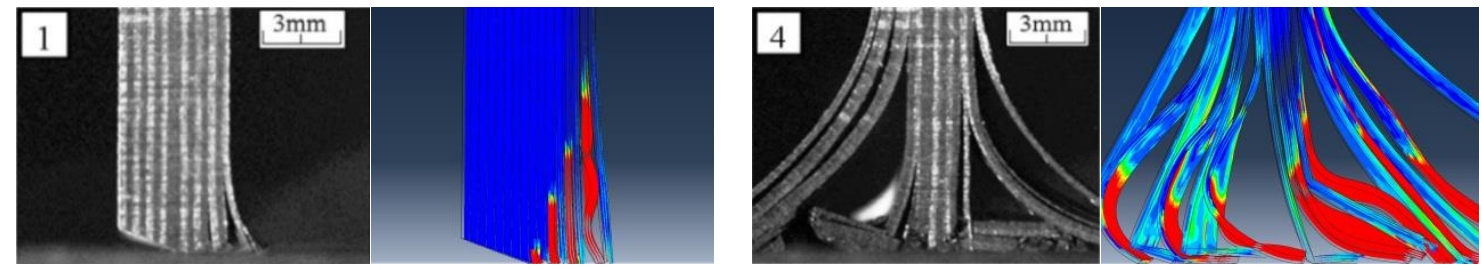

(a)

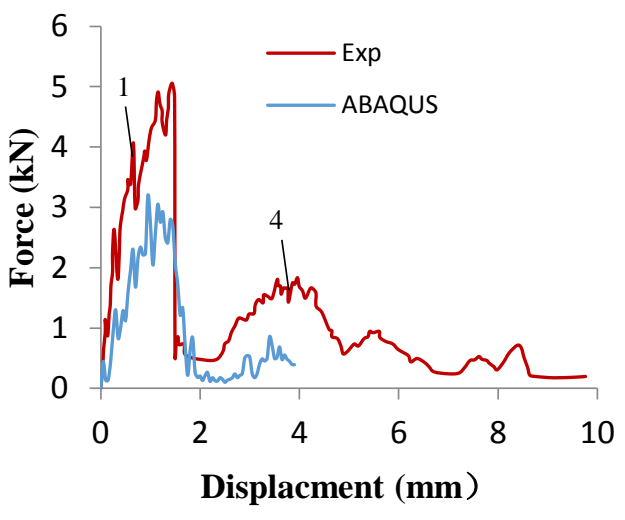

(b)

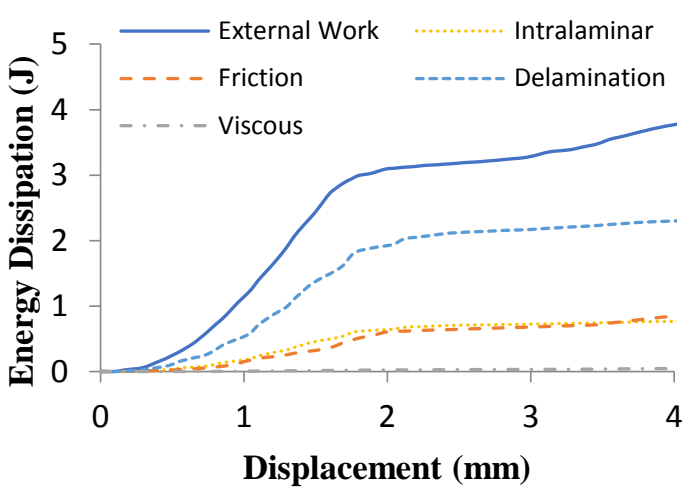

(c)

Fig. 18. (a) Experimental morphologies and Hashin's compressive matrix damage contour; (b) force-displacement curve of crushing test on $\left[\left(0^{\circ} / 90^{\circ}\right)_{4}\right]_{\mathrm{s}}-20^{\circ}$ specimen; (c) energy dissipation- displacement curves 
Tables

Table 1. Specimen configurations

\begin{tabular}{ccccccc}
\hline ID & Specimens & Material & Thickness $(\mathrm{mm})$ & Width $(\mathrm{mm})$ & Height $(\mathrm{mm})$ & Trigger $\left({ }^{\circ}\right)$ \\
\hline A $\left[\left(0^{\circ} / 90^{\circ}\right)_{4}\right]_{\mathrm{s}}$ & T700/M21 & 4.16 & 8.32 & 60 & 20 \\
B & {$\left[0^{\circ}\right]_{8}$} & T700/M21 & 2.13 & 10.23 & 60 & 20 \\
C & {$\left[90^{\circ}\right]_{8}$} & T700/M21 & 2.13 & 10.23 & 60 & 20 \\
D $\left[\left(0^{\circ} / 90^{\circ}\right)_{4}\right]_{\mathrm{s}}$ & T700/M21 & 4.16 & 10 & 60 & 45 \\
E & {$\left[90^{\circ}\right]_{8}$} & T700/MTM57 & 2.50 & 13 & 20 & 10 \\
\hline
\end{tabular}


Table 2. Material Properties of T700/M21 for numerical simulation [26]

\begin{tabular}{ll}
\hline \multicolumn{1}{c}{ Property } & \multicolumn{1}{c}{ Values } \\
\hline \multirow{2}{*}{ Elastic Properties } & $\mathrm{E}_{1}=130 \mathrm{GPa} ; \mathrm{E}_{2}=\mathrm{E}_{3}=9.0 G P a ; \mathrm{G}_{23}=5.0 G P a ;$ \\
& $\mathrm{G}_{12}=\mathrm{G}_{13}=5.0 G P a ; v_{12}=v_{13}=0.33 ; v_{23}=0.35$ \\
\hline \multirow{2}{*}{ Strength } & $\mathrm{X}^{\mathrm{T}}=2080 \mathrm{MPa} ; \mathrm{X}^{\mathrm{C}}=1250 \mathrm{MPa} ; \mathrm{Y}^{\mathrm{T}}=75 \mathrm{MPa} ;$ \\
& $\mathrm{Y}^{\mathrm{C}}=120 \mathrm{MPa} ; \mathrm{S}_{12}=110 \mathrm{MPa}$ \\
\hline \multirow{2}{*}{ Intralaminar Fracture Toughness } & $\Gamma_{11}^{\mathrm{T}}=133 \mathrm{~N} / \mathrm{mm} ; \Gamma_{11}^{\mathrm{C}}=40 \mathrm{~N} / \mathrm{mm} ; \Gamma_{22}^{\mathrm{T}}=0.6 \mathrm{~N} /$ \\
& $\mathrm{mm} ; \Gamma_{22}^{\mathrm{C}}=2.1 \mathrm{~N} / \mathrm{mm} ; \Gamma_{12, \mathrm{C}}=\Gamma_{23, \mathrm{C}}=2.1 \mathrm{~N} / \mathrm{mm} ;$ \\
\hline Non-linear Shear Properties $[49]$ & $\mathrm{c}_{1}=37833 \mathrm{MPa} ; \mathrm{c}_{2}=16512 \mathrm{MPa} ; \mathrm{c}_{3}=2334.3 \mathrm{MPa}$ \\
Interface Properties & $G_{I}=0.6 \mathrm{~N} / \mathrm{mm} ; \mathrm{G}_{I I}=2.1 \mathrm{~N} / \mathrm{mm} ; \eta=1.45$ \\
\hline
\end{tabular}


Table 3. Material Properties of T700/MTM57 for numerical simulation [21]

\begin{tabular}{ll}
\hline \multicolumn{1}{c}{ Property } & \multicolumn{1}{c}{ Values } \\
\hline \multirow{2}{*}{ Elastic Properties } & $\mathrm{E}_{1}=128 \mathrm{GPa} ; \mathrm{E}_{2}=\mathrm{E}_{3}=7.9 \mathrm{GPa} ; \mathrm{G}_{23}=2.5 \mathrm{GPa} ;$ \\
& $\mathrm{G}_{12}=\mathrm{G}_{13}=3.0 \mathrm{GPa} ; \mathrm{v}_{12}=v_{13}=0.3 ; \mathrm{v}_{23}=0.4$ \\
\hline \multirow{2}{*}{ Strength [19] } & $\mathrm{X}^{\mathrm{T}}=2481 \mathrm{MPa} ; \mathrm{X}^{\mathrm{C}}=1296 \mathrm{MPa} ; \mathrm{Y}^{\mathrm{T}}=52.9 \mathrm{MPa} ;$ \\
\hline \multirow{2}{*}{ Intralaminar Fracture Toughness } & $\mathrm{Y}^{\mathrm{C}}=242 \mathrm{MPa} ; \mathrm{S}_{12}=91.3 \mathrm{MPa}$ \\
\hline Non-linear Shear Properties & $\Gamma_{11}^{\mathrm{T}}=92 \mathrm{~N} / \mathrm{mm}^{b} ; \Gamma_{11}^{\mathrm{C}}=35 \mathrm{~N} / \mathrm{mm}^{b} ; \Gamma_{22}^{\mathrm{T}}=0.26 \mathrm{~N} /$ \\
Interface Properties & $\mathrm{mm}^{b} ; \Gamma_{22}^{\mathrm{C}}=1.2 \mathrm{~N} / \mathrm{mm} ; \Gamma_{12, \mathrm{C}}=\Gamma_{23, \mathrm{C}}=1.2 \mathrm{~N} / \mathrm{mm} ;$ \\
\hline${ }^{\mathrm{a}}$ Estimated value from $\mathrm{C}_{23}=55932 \mathrm{MPa} ; \mathrm{c}_{2}=19148 \mathrm{MPa} ; \mathrm{c}_{3}=2046 \mathrm{MPa}$ \\
\hline
\end{tabular}

